University of Wollongong

Research Online

Australian Institute for Innovative Materials -

Papers

Australian Institute for Innovative Materials

$1-1-2019$

\title{
Lotus rhizome-like S/N-C with embedded WS2 for superior sodium storage
}

Xiu Li

University of Wollongong, Chinese Academy of Sciences, x1816@uowmail.edu.au

Yonggang Sun

Chinese Academy Of Sciences

Xun Xu

University of Wollongong, xun@uow.edu.au

Yunxiao Wang

University of Wollongong, yunxiao@uow.edu.au

Shulei Chou

University of Wollongong, shulei@uow.edu.au

See next page for additional authors

Follow this and additional works at: https://ro.uow.edu.au/aiimpapers

Part of the Engineering Commons, and the Physical Sciences and Mathematics Commons

Research Online is the open access institutional repository for the University of Wollongong. For further information contact the UOW Library: research-pubs@uow.edu.au 


\title{
Lotus rhizome-like S/N-C with embedded WS2 for superior sodium storage
}

\author{
Abstract \\ Sodium-ion batteries (SIBs) hold great promise as power sources because of their low cost and decent \\ electrochemical behavior. Nevertheless, the poor rate performance and long-term cycling capability of \\ anode materials in SIBs still impede their practical application in smart grids and electric vehicles. Herein, \\ we design a delicate method to embed WS2 nanosheets into lotus rhizome-like heteroatom-doped carbon \\ nanofibers with abundant hierarchical tubes inside, forming WS2@sulfur and nitrogen-doped carbon \\ nanofibers (WS2@S/N-C). The WS2@S/N-C nanofibers exhibit a large discharge capacity of $381 \mathrm{~mA}$ h g-1 \\ at $100 \mathrm{~mA} \mathrm{~g}-1$, excellent rate capacity of $108 \mathrm{~mA} \mathrm{~h} \mathrm{g-1}$ at $30 \mathrm{~A} \mathrm{~g}-1$, and a superior capacity of $175 \mathrm{~mA} \mathrm{~h}$ \\ g-1 at $5 \mathrm{~A} \mathrm{g-1}$ after 1000 cycles. The excellent performance of WS2@S/N-C is ascribed to the synergistic \\ effects of WS2 nanosheets, contributing to larger interlayer spacing, and the stable lotus rhizome-like S/ \\ $\mathrm{N}-\mathrm{C}$ nanofiber frameworks which alleviate the mechanical stress. Moreover, the WS2@S/N-C electrode \\ shows obvious pseudocapacitive properties at $1 \mathrm{mV} \mathrm{s}-1$ with a capacitive contribution of $86.5 \%$. In \\ addition, density functional theory calculations further indicate that the WS2@S/N-C electrode is very \\ favorable for $\mathrm{Na}$ storage. This novel synthetic strategy is a promising method for synthesizing other \\ electrode materials for rechargeable batteries in the future. \\ Keywords \\ rhizome-like, s/n-c, embedded, lotus, ws2, storage, superior, sodium \\ Disciplines \\ Engineering | Physical Sciences and Mathematics \\ Publication Details \\ Li, X., Sun, Y., Xu, X., Wang, Y., Chou, S., Cao, A., Chen, L. \& Dou, S. (2019). Lotus rhizome-like S/N-C with \\ embedded WS2 for superior sodium storage. Journal of Materials Chemistry A, 7 (45), 25932-25943.

\section{Authors} \\ Xiu Li, Yonggang Sun, Xun Xu, Yunxiao Wang, Shulei Chou, Anmin Cao, Libao Chen, and Shi Xue Dou
}




\section{Lotus Rhizome-like S/N-C for Strengthening $\mathrm{WS}_{2}$ with Superior Sodium Storage}

Xiu Li, ${ }^{a, b}$ Yonggang Sun, ${ }^{b}$ Xun Xu, ${ }^{a}, *$ Yunxiao Wang, ${ }^{a} *$ Shulei Chou, ${ }^{a}$ Anmin Cao,${ }^{b}$ Libao Chen, ${ }^{c, *}$ and Shixue Dou ${ }^{a}$

anstitute for Superconducting and Electronic Materials, University of Wollongong, Wollongong, NSW 2500, Australia.

${ }^{\mathrm{b}}$ Key Laboratory of Molecular Nanostructure and Nanotechnology and Beijing National Laboratory for Molecular Sciences, Institute of Chemistry, Chinese Academy of Sciences (CAS), Beijing 100190, P. R. China

'State Key Laboratory of Powder Metallurgy, Central South University, Changsha, Hunan 410083, P. R. China

Corresponding authors: Xun $\mathrm{Xu}$, Yunxiao Wang andLibao Chen

Email: xun@uow.edu.au (Dr. X. Xu);

yunxiao@uow.edu.au (Dr. Y. Wang)

lbchen@csu.edu.cn (Prof. L. Chen) 


\begin{abstract}
Sodium-ion batteries (SIBs) hold great promise as power sources because of their low cost and decent electrochemical behavior. Nevertheless, the poor rate performance and long-term cycling capability of anode materials in SIBs still impede their practical applications in smart grids and electric vehicles. Herein, we design a delicate method to embed $\mathrm{WS}_{2}$ nanosheets into lotus rhizome-like heteroatom-doped carbon nanofibers with abundant hierarchical tubes inside, forming WS $\mathrm{WS}_{2} @$ sulfur and nitrogen-doped carbon nanofibers (WS $\left.\mathrm{WS}_{2} @ \mathrm{~S} / \mathrm{N}-\mathrm{C}\right) . \mathrm{The}_{\mathrm{WS}} @ \mathrm{~S} / \mathrm{N}-\mathrm{C}$ nanofibers exhibit a large discharge capacity of $381 \mathrm{~mA} \mathrm{~h} \mathrm{~g}^{-1}$ at $100 \mathrm{mAg}^{-1}$, excellent rate capacity of $108 \mathrm{~mA} \mathrm{~h} \mathrm{~g}^{-1}$ at $30 \mathrm{~A} \mathrm{~g}^{-1}$, and a superior capacity of $175 \mathrm{~mA} \mathrm{~h} \mathrm{~g}^{-1}$ at $5 \mathrm{Ag}^{-1}$ after 1000 cycles. The excellent performance of $\mathrm{WS}_{2} @ \mathrm{~S} / \mathrm{N}-\mathrm{C}$ is ascribed to the synergistic effects of $\mathrm{WS}_{2}$ nanosheets, contributing to larger interlayer spacing, and the stable lotus rhizome-like S/N-C nanofiber frameworks to alleviate the mechanical stress. Moreover, the $\mathrm{WS}_{2} @ \mathrm{~S} / \mathrm{N}-\mathrm{C}$ electrode shows an obvious pseudocapacitance property at $1 \mathrm{mV} \mathrm{s}^{-1}$ with a capacitive contribution of $86.5 \%$. In addition, the density functional theory calculations further indicate that $\mathrm{WS}_{2} @ \mathrm{~S} / \mathrm{N}-\mathrm{C}$ electrode is very favorable for $\mathrm{Na}$ storage. This novel synthetic strategy is a promising method for synthesizing other electrode materials for rechargeable batteries in the future.
\end{abstract}

Keywords: Tungsten disulfide; carbon; doping; anode; sodium-ion batteries 


\section{Introduction}

Sodium-ion batteries (SIBs) have promisingly replaced for lithium-ion batteries (LIBs) as power sources for smart grids and low-speed electric vehicles, owing to the low cost and abundance of sodium $(\mathrm{Na})$ resources and their high safety due to the high potential of $\mathrm{Na}(-2.714 \mathrm{~V}){ }^{1-3}$ Nevertheless, the radius of Na-ions $(1.06 \AA)$ is larger than that of lithium (Li) ions (0.76 $\AA$ ), leading to sluggish diffusion kinetics for $\mathrm{Na}^{+}$, making it difficult to find appropriate anode materials with larger interlayer spacing and good reversible $\mathrm{Na}^{+}$storage for SIBs. ${ }^{4,}{ }^{5}$ So far, a large number of a node materials have been explored for SIBs, including carbonaceous materials, ${ }^{6-8}$ alloying reaction metals and alloys ( $\mathrm{Sn}, \mathrm{Sb}, \mathrm{Bi}$, and their alloys), ${ }^{9-12}$ metal oxides ${ }^{13-15}$ and chalcognides, ${ }^{16-18}$ and others. Among them, carbonaceous materials usually exhibit excellent cycling performance, although they possess relatively low capacity. ${ }^{19-21}$ The alloyed metal materials always show high theoretical capacity, but the large volume change problem during the alloying/de-alloying process leads to poor rate capability.22 In addition, the large volume expansion for $\mathrm{Na}^{+}$storage due to the formation of $\mathrm{Na}_{2} \mathrm{O}$ and $\mathrm{Na}_{2} \mathrm{~S}$ (or $\left.\mathrm{Na}_{2} \mathrm{Se}\right)^{23-26}$ will shorten the cycling life of these anode compounds. Therefore, it is essential to find effective strategies to obtain excellent anode materials with well-balanced performance in terms of high capacity, excellent rate capability, and long-term cycling stability.

two-dimensional (2D) transition-metal dichalcogenides (TMDCs) have obtained great interest as anode materials for SIBs due to their unique layered structure. ${ }^{27,}{ }^{28}$ As one example of typical TMDCs, tungsten disulfide $\left(\mathrm{WS}_{2}\right)$ exhibits larger layer spacing with weak van der Waals interaction and higher electrical conductivity than the traditional $\mathrm{MoS}_{2} \cdot{ }^{29}$ Benefiting from its structural characteristics and conductive nature, the $\mathrm{WS}_{2}$ anode material exhibits high rate capability for SIBs,${ }^{30-33}$ although the long-term cycling performance of $\mathrm{WS}_{2}$ as anode for SIBs is not satisfactory for practical application. ${ }^{34}$ Actually, this is a common issue for metal sulfides as electrode materials for LIBs and SIBs because the cycling life is strongly influenced by certain factors, ${ }^{34-36}$ i.e., the large volume changes during electrochemical processes, the $\mathrm{Li}^{+} / \mathrm{Na}^{+}$diffusion kinetics, and the obvious dissolution of the polysulfide intermediates. Thus, it is desirable to look for effective means to solve the problem of $\mathrm{WS}_{2}$ as anode material, endowing it with stable long-term cycling and high rate capability.

Carbon scaffolds have been employed to effectively host metal sulfides as electrode 
materials, ${ }^{37-39}$ i.e., one-dimensional (1D) carbon nanofibers, graphene, or mesoporous carbon. Among them, the carbon nanofibers have been demonstrated to be a good substrate for hosting metal sulfides as anode materials. ${ }^{40-44}$ First, their highly conductive nature, along with the large longitudinal aspect ratio of carbon nanofibers could facilitate electron transfer among the metal sulfide particles and improve the $\mathrm{Na}^{+}$diffusion kinetics at the same time, resulting in high rate capability for electrodes. Second, carbon nanofibers can alleviate the mechanical stress during the electrochemical process and prevent the pulverization of the embedded metal sulfide materials, which can yield electrodes that have stable long cycling performance. Last but not least, heteroatom doping is favorable to improve the capacity of carbon nanofibers as electrodes, which can be easily prepared by electrospinning. Based on the above analysis, it would be a promising method to achieve enhanced sodium storage performance with large capacity, excellent rate capability, and cycling stability by embedding $\mathrm{WS}_{2}$ nanosheets in heteroatom doped carbon nanofibers.

Herein, we have designed a novel method to prepare lotus rhizome-like $\mathrm{WS}_{2} @ \mathrm{~S} / \mathrm{N}$-co-doped carbon nanofibers (denoted as $\mathrm{WS}_{2} @ \mathrm{~S} / \mathrm{N}-\mathrm{C}$ ) to realize the above targets. The synthetic procedures are shown in Scheme 1. The $\mathrm{WO}_{3}$ nanosheets are first synthesized via the hydrothermal method, and then embedded into polymer nanofibers via electrospinning. Subsequently, WS $\mathrm{S}_{2} @ \mathrm{~S} / \mathrm{N}-\mathrm{C}$ nanofibers are obtained through carbonizing the $\mathrm{WO}_{3} /$ poly-acrylonitrile/polymethyl methacrylate (PAN/PMMA) nanofibers with sulfur, with the process including preheating at $230{ }^{\circ} \mathrm{C}$ and further annealing at $600^{\circ} \mathrm{C}$. The designed $\mathrm{WS}_{2} @ \mathrm{~S} / \mathrm{N}-\mathrm{C}$ nano-architecture offers various advantages: i) the embedding of $\mathrm{WS}_{2}$ nanosheets in carbon nanofibers could enhance the overall electrode conductivity, offering high accessible capacity; ii) the formation of lotus rhizome-like carbon nanofibers could facilitate electron transfer and prevent the pulverization of the electrode structure, resulting in a stable long-term cycling life span. The $\mathrm{WS}_{2} @ \mathrm{~S} / \mathrm{N}-\mathrm{C}$ electrode presents a high rate capacity of $108 \mathrm{~mA} \mathrm{~h} \mathrm{~g}^{-1}$ at $30 \mathrm{~A} \mathrm{~g}^{-1}$, a good reversible capacity of $321 \mathrm{~mA} \mathrm{~h} \mathrm{~g}^{-1}$ at $100 \mathrm{~mA} \mathrm{~g}^{-1}$ (vs. $25 \mathrm{~mA} \mathrm{~h} \mathrm{~g}^{-1}$ for $\mathrm{WS}_{2}$ ) after 100 cycles, and a stable capacity of $175 \mathrm{~mA} \mathrm{~h} \mathrm{~g}^{-1}$ at $5 \mathrm{~A} \mathrm{~g}^{-1}$ after 1000 cycles. In addition, both the kinetics calculations and the theoretical analysis demonstrate that $\mathrm{S} / \mathrm{N}-\mathrm{C}$ nanofibers could improve the rate capability of $\mathrm{WS}_{2}$ materials. 


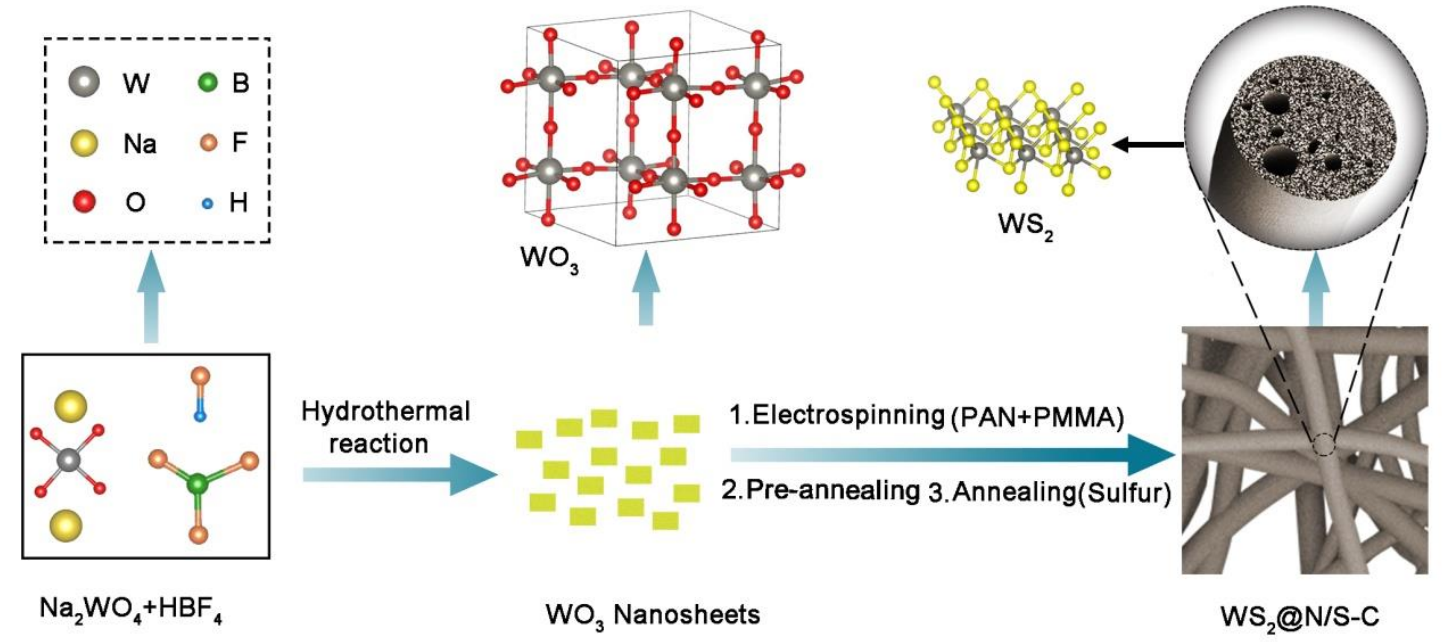

Scheme 1. Schematic illustration of the synthetic route to prepare the porous $\mathrm{WS}_{2} @ \mathrm{~S} / \mathrm{N}-\mathrm{C}$ nanofibers.

\section{Experimental section}

\subsection{Synthesis of $\mathrm{WO}_{3}$ nanosheets}

$\mathrm{WO}_{3}$ nanosheets were synthesized according to the literature with minor modification. ${ }^{45}$ Typically, $1.0 \mathrm{~g} \mathrm{Na}_{2} \mathrm{WO}_{4} \cdot 2 \mathrm{H}_{2} \mathrm{O}$ was first dissolved in $40 \mathrm{~mL}$ water, and then $3.0 \mathrm{~mL} \mathrm{HBF}_{4}$ solution ( $40 \%$ by weight) was dropped into the solution. After that, the mixture was maintained under hydrothermal conditions at $100{ }^{\circ} \mathrm{C}$ for $10 \mathrm{~h}$. Finally, the resulting product was collected with distilled water and absolute ethanol to obtain the pure $\mathrm{WO}_{3}$.

\subsection{Synthesis of WS $S_{2} @ S / N-C$ nanofibers}

The WS $\mathrm{W}_{2} @ \mathrm{~S} / \mathrm{N}-\mathrm{C}$ nanofibers were produced through the electrospinning method. In a typical synthesis, $0.24 \mathrm{~g}$ PMMA and $0.36 \mathrm{~g}$ PAN were firstly dissolved in $5 \mathrm{~mL}$ dimethylformamide (DMF) solution under vigorous stirring at $60{ }^{\circ} \mathrm{C}$ for $4 \mathrm{~h}$. Then, $0.3 \mathrm{~g}$ as-synthesized $\mathrm{WO}_{3}$ were added in the above solution to obtain a stable suspension for the electrospinning with an applied voltage of $13 \mathrm{kV}$ and a feeding rate of $0.3 \mathrm{~mL} \mathrm{~h}^{-1}$. Moreover, the distance between the stainless steel needle and the collector was set to be $15 \mathrm{~cm}$. To stabilize the structure, the obtained fiber-like membrane was annealed at $230^{\circ} \mathrm{C}$ for $2 \mathrm{~h}$ in air. The pretreated nanofibers were further carbonized with sulfur powder (mass ratio of 1:4) in flowing Ar. The nanofibers and sulfur were carbonized at $600{ }^{\circ} \mathrm{C}$ for $2 \mathrm{~h}$ to transform the $\mathrm{WO}_{3}$ into $\mathrm{WS}_{2}$ in carbon nanofibers. 
For comparison, $0.3 \mathrm{~g} \mathrm{WO}_{3}$ and $1.2 \mathrm{~g}$ sulfur power were further carbonized by the same method to transform the $\mathrm{WO}_{3}$ into $\mathrm{WS}_{2}$. In addition, $\mathrm{S} / \mathrm{N}-\mathrm{C}$ nanofibers were synthesized according to the similar procedure without $\mathrm{WO}_{3}$ precursor.

\subsection{Material characterizations}

The morphologies and structure of the as-synthesized samples were measured by field emission scanning electron microscopy (FE-SEM, Helios Nanolab G3UC) equipped with Energy Dispersive Spectrometer (EDS) and field emission transmission electron microscopy (TEM, FEI Titan G2 60-300). The crystal structure and phase composition were confirmed by X-ray powder diffraction (XRD, Rigaku D/Max-2500). Raman spectroscopy (DXR microscope, Thermo Fischer DXR) was carried out with $532 \mathrm{~nm}$ laser as excitation resource. Fourier transform infrared spectra were also collected (FT-IR, Nicolet-460). Thermogravimetric analysis (TGA, SDTQ600) was used to confirm the content of $\mathrm{WS}_{2}$ in the composite. The chemical states of the samples were investigated by X-ray photoelectron spectroscopy (XPS, Escalab 250Xi). Nitrogen adsorption and desorption isotherms (BET, Tristar 3020) was used to determine the Brunauer-Emmett-Teller (BET) surface area.

\subsection{Electrochemical measurements}

All the electrochemical tests were carried out using 2025 coin-type half cells. The working electrodes were prepared by mixing the active material powder, acetylene black, and carboxymethyl cellulose (CMC) in a weight ratio of 8:1:1 to form a slurry, which was then spread onto $\mathrm{Cu}$ foil, subsequently dried in a vacuum oven at $60^{\circ} \mathrm{C}$ for $12 \mathrm{~h}$, and then cut into 12 mm-diameter discs. The mass loading amount of the active material was about $0.7-0.8 \mathrm{mg} \mathrm{cm}^{-2}$. Half cells were made up using Na metal as the counter electrode and glass fiber as the separator were assembled in an Ar-filled glove box. The electrolyte was $1 \mathrm{M} \mathrm{NaClO}_{4}$ dissolved in a mixture of ethylene carbonate (EC) and diethyl carbonate (DEC) (1: 1 by volume ratio) with $5 \mathrm{wt} \%$ fluoroethylene carbonate (FEC). The galvanostatic charge/discharge tests were performed on a battery test system (Land CT2001A), and the cyclic voltammetry (CV) was carried out on an electrochemical workstation (CHI660E), both in the voltage range of 0.01-3 V. All the electrochemical tests were conducted at room temperature.

\subsection{Calculation details}

To investigate the reasons for the enhanced sodium storage performance, density functional theory 
(DFT) calculations were used to investigate the adsorption behavior of $\mathrm{Na}$ on the pristine $\mathrm{WS}_{2}$ and $\mathrm{WS}_{2}$ with N/S-doped graphene (WS $/ \mathrm{WS}_{2} @$ graphene) by using the Vienna Ab-initio Simulation Package (VASP). ${ }^{46,} 47$ The exchange-correlation functional,were determined by the generalized gradient approximation (GGA) with the Perdew-Burke-Ernzerhof (PBE) form. ${ }^{48}$ The frozen-core projector-augmented wave (PAW) method $^{49,50}$ was used for interactions between the core electrons and the valence electrons. The convergence criterion was set at $10^{-5} \mathrm{eV}$, and atomic positions were allowed to move until the forces acting on each atoms were less than $0.02 \mathrm{eV} / \hat{\AA}$ for the total energy calculations, with a high energy cut-off of $520 \mathrm{eV}$. The Brillouin zone was integrated with $3 \times 3 \times 1$ Monkhorst-Pack k-point grids for geometry optimization. Moreover, The vacuum space of $20 \AA$ was used in the z-direction could avoid any interaction between the adjacent repeating layers.

The adsorption energy $\left(E_{a d}\right)$ of at $\mathrm{Na}$ atom sites in $\mathrm{WS}_{2}$ and $\mathrm{WS}_{2}$ with $\mathrm{N}, \mathrm{S}$ doped graphene $\left(\mathrm{WS}_{2} / \mathrm{NSG}\right)$ was calculated as follows:

$$
E_{a d}=E_{\mathrm{WS} 2-\mathrm{Na}, \mathrm{WS} 2 / \mathrm{NSG}-\mathrm{Na}}-E_{\mathrm{WS} 2, \mathrm{WS} 2 / \mathrm{NSG}}-E_{N a}
$$

Where $E_{\mathrm{WS} 2-\mathrm{Na}, \mathrm{WS} 2 / \mathrm{NSG}-\mathrm{Na}}$ is the total energy for one $\mathrm{Na}$ atom in $\mathrm{WS}_{2}$ and $\mathrm{WS}_{2} / \mathrm{NSG}$; $E_{\mathrm{WS} 2, \mathrm{WS} 2 / \mathrm{NSG}}$ is the total energy for $\mathrm{WS}_{2}$ and $\mathrm{WS}_{2} / \mathrm{NSG}$ without the adsorption of $\mathrm{Na} ; E_{N a}$ is for one $\mathrm{Na}$ atom in the same slab.

Herein, both the interaction between $\mathrm{WS}_{2}$ or $\mathrm{WS}_{2} / \mathrm{NSG}$ and a $\mathrm{Na}$ ion indicates massive charge transfer, which can be visualized by three-dimensional charge difference mapping, and the definition is as follow:

$$
\Delta \rho=\rho_{\mathrm{WS} 2-\mathrm{Na}, \mathrm{WS} 2 / \mathrm{NSG}-\mathrm{Na}}-\rho_{\mathrm{WS} 2, \mathrm{WS} 2 / \mathrm{NSG}}-\rho_{N a}
$$

Where $\rho_{\mathrm{WS} 2-\mathrm{Na}, \mathrm{WS} 2 / \mathrm{NSG}-\mathrm{Na}}$ is the charge density of the composite or $\mathrm{WS}_{2}$ with one $\mathrm{Na}$ atom adsorbed; $\rho_{\mathrm{WS} 2, \mathrm{WS} 2 / \mathrm{NSG}}$ is the charge density of the composite or $\mathrm{WS}_{2}$ without $\mathrm{Na} ; \rho_{\mathrm{Na}}$ is the charge density of one $\mathrm{Na}$ atom in the same slab, respectively.

\section{Results and discussion}



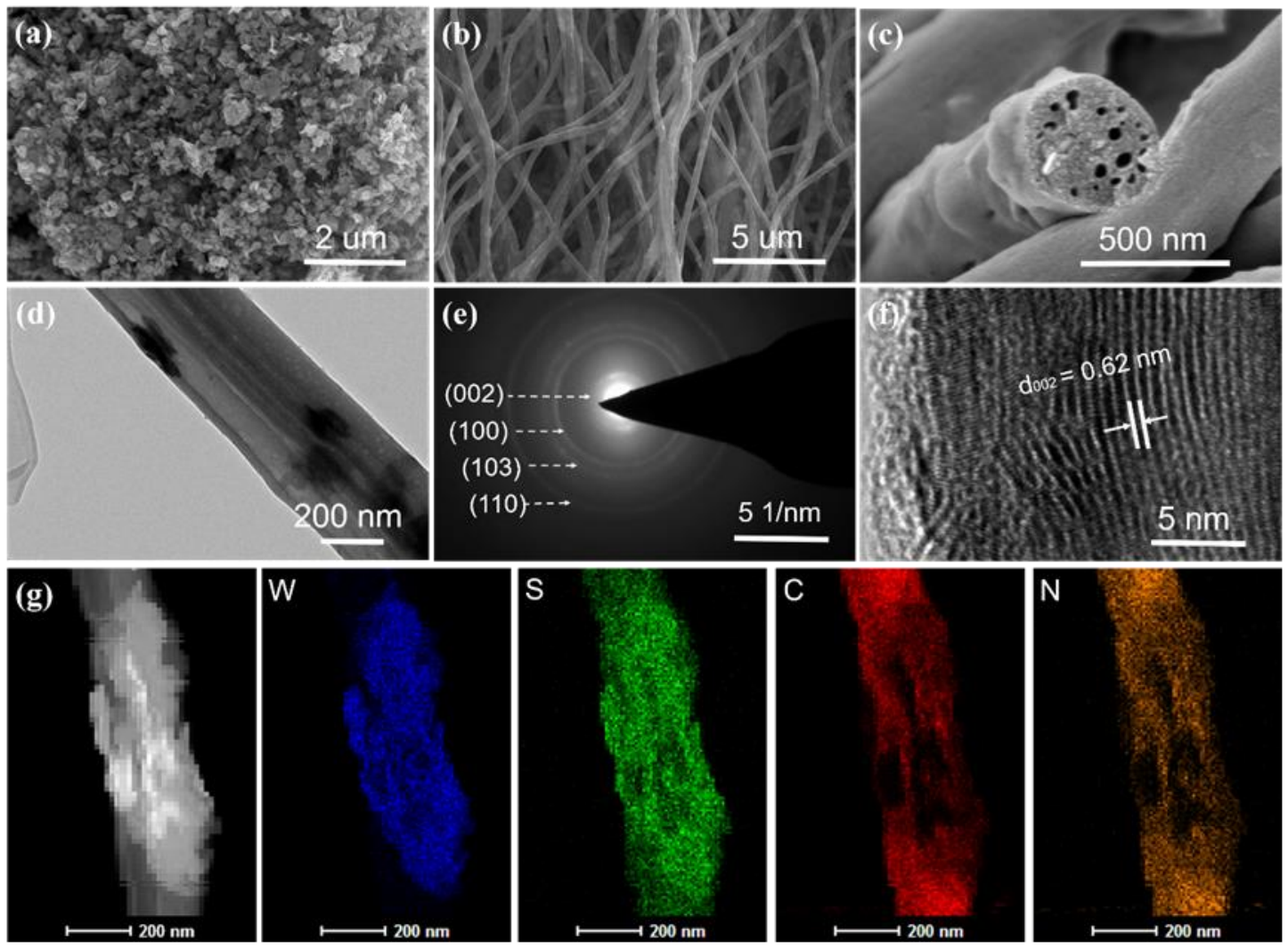

Figure 1 (a) Low-resolution SEM image of $\mathrm{WO}_{3}$ nanosheets; (b) low-resolution and (c) high-resolution SEM images, (d) low-resolution TEM image, (e) electron diffraction pattern, (f) high-resolution TEM image, and (g) element mapping of $\mathrm{WS}_{2} @ \mathrm{~S} / \mathrm{N}-\mathrm{C}$.

The structure and morphology of the samples were investigated by SEM and TEM, The SEM image in Figure 1a exhibits the as-synthesized $\mathrm{WO}_{3}$ nanosheets with about $40 \mathrm{~nm}$ in size, which could be electrospun into PAN/PMMA, and further changed into WS $\mathrm{W}_{2} @ \mathrm{~S} / \mathrm{N}-\mathrm{C}$ nanofibers through a carbonization and sulfidation process. In Figure 1b, WS $\mathrm{W}_{2} @ \mathrm{~S} / \mathrm{N}-\mathrm{C}$ nanofibers exhibit a length of several tens micrometers and a diameter of $400 \mathrm{~nm}$. The WS $\mathrm{S}_{2} @ \mathrm{~S} / \mathrm{N}-\mathrm{C}$ nanofibers in Figure 1c are observed to be porous like lotus rhizomes due to the decomposition of PMMA during the carbonization process. The embedding could prevent the aggregation of $\mathrm{WS}_{2}$ nanosheets (Figure S1a and $\mathbf{b}$ in the Supporting Information) during the sulfidation process. In Figure 1d, there are some dark parts in the single nanofiber owing to the presence of $\mathrm{WS}_{2}$ nanosheets embedded in the carbon nanofibers. The selected area electron diffraction (SAED) pattern of $\mathrm{WS}_{2}$ nanosheets in the WS $S_{2} @$ S/N-C nanofibers is shown in Figure 1e. The diffraction rings from inside to outside are attributed to the (002), (100), (103), and (110) planes, respectively. The high-resolution TEM 
(HRTEM) image of the vertically grown $\mathrm{WS}_{2}$ nanosheets in Figure 1f displays a $0.62 \mathrm{~nm}$ interlayer spacing, which can be attributed to the (002) planes of hexagonal $\mathrm{WS}_{2}$, consistent with the XRD results for $\mathrm{WS}_{2} @ \mathrm{~S} / \mathrm{N}-\mathrm{C}$. This value is in accord with the theoretical interlayer spacing along the $c$-axis direction. The pure $\mathrm{WS}_{2}$ shows similar results in Figure S1c and $\mathbf{d}$. The energy dispersive X-ray (EDX) element mapping images indicate that the $\mathrm{W}, \mathrm{S}, \mathrm{C}$, and $\mathrm{N}$ elements are not uniformly distributed throughout the $\mathrm{WS}_{2} @ \mathrm{~S} / \mathrm{N}-\mathrm{C}$ nanofiber (Figure 1g), which is due to the distribution of the isolated nanosheets.
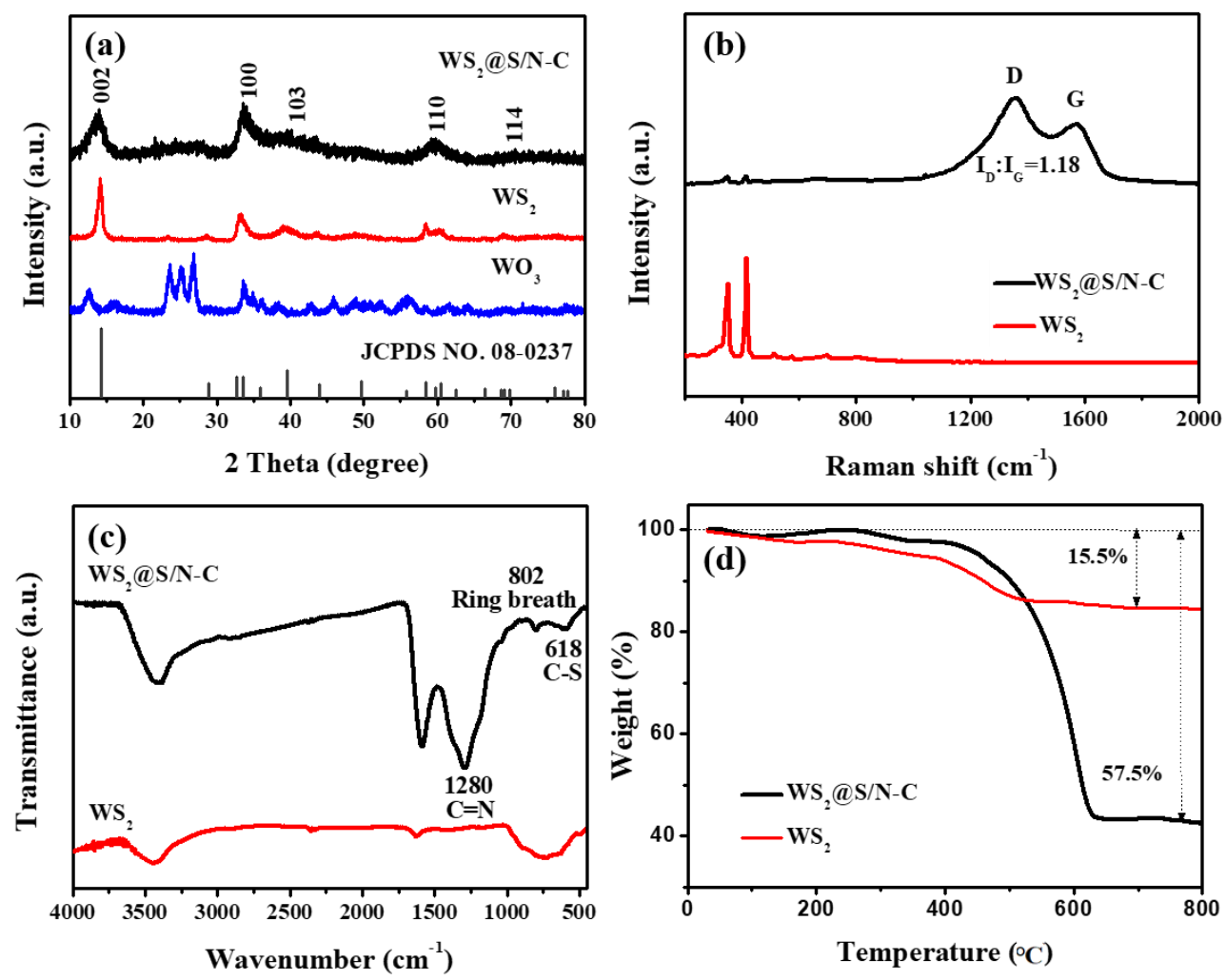

Figure 2 (a) XRD patterns of $\mathrm{WO}_{3}, \mathrm{WS}_{2}$, and $\mathrm{WS}_{2} @ \mathrm{~S} / \mathrm{N}-\mathrm{C}$; (b) Raman spectra, (c) FT-IR spectra, and (d) TGA curves of $\mathrm{WS}_{2}$ and $\mathrm{WS}_{2} @ \mathrm{~S} / \mathrm{N}-\mathrm{C}$.

The components and crystalline phases of the materials were characterized by the XRD. Figure 2a compares the XRD patterns of the $\mathrm{WO}_{3}, \mathrm{WS}_{2}$, and $\mathrm{WS}_{2} @ \mathrm{~S} / \mathrm{N}-\mathrm{C}$ samples. The diffraction peaks of the pristine $\mathrm{WO}_{3}$ can be well assigned to a monoclinic phase, and the phase transition from monoclinic $\mathrm{WO}_{3}$ to hexagonal $\mathrm{WS}_{2}$ accompanies the carbonization of $\mathrm{WO}_{3}$ with sulfur to develop $\mathrm{WS}_{2}$. Strong peaks located at $14.3,32.76,39.5,58.4$, and $66.5^{\circ}$ can be indexed to the (002), (100), (103), (110), and (114) planes of the hexagonal structure of $\mathrm{WS}_{2}$ (JCPDS no. 08-0237), respectively. Moreover, the obviously weaker intensity of $\mathrm{WS}_{2} @ \mathrm{~S} / \mathrm{N}-\mathrm{C}$ compared to the $\mathrm{WS}_{2}$ 
implies that the sample was successfully wrapped by carbon nanofibers, which may have restricted the volume changes, preventing the pulverization of the electrode structure over a long-term cycling lifespan. Further structural information on the $\mathrm{WS}_{2} @ \mathrm{~S} / \mathrm{N}-\mathrm{C}$ and $\mathrm{WS}_{2}$ was acquired by Raman spectroscopy and FTIR analysis. The peaks of the $\mathrm{WS}_{2}$ and $\mathrm{WS}_{2} @ \mathrm{~S} / \mathrm{N}-\mathrm{C}$ samples in the Raman spectra (Figure 2b) are located at 351 and $416 \mathrm{~cm}^{-1}$, and can be ascribed to the Raman active $\mathrm{E}_{2 \mathrm{~g}}$ and $\mathrm{A}_{1 \mathrm{~g}}$ vibration modes for $\mathrm{WS}_{2} .{ }^{33}$ Compared to the $\mathrm{WS}_{2}$, there is weaker intensity for WS $\mathrm{W}_{2} @ \mathrm{~S} / \mathrm{N}-\mathrm{C}$ due to the wrapping with carbon nanofibers. The peaks around 1350 and $1560 \mathrm{~cm}^{-1}$ are attributed to the disorder-induced $\mathrm{D}$ band and the graphitic $\mathrm{G}$ band for the $\mathrm{WS}_{2} @ \mathrm{~S} / \mathrm{N}-\mathrm{C}$ sample, respectively. In addition, the intensity ratio of the D-band to G-band (1.3, $\left.I_{\mathrm{D}}: I_{\mathrm{G}}\right)$ implies that more defects exist in $\mathrm{WS}_{2} @ \mathrm{~S} / \mathrm{N}-\mathrm{C}$, which is associated with the $\mathrm{N}$, S-co-doping. ${ }^{51}$ In the FTIR spectrum of $\mathrm{WS}_{2} @ \mathrm{~S} / \mathrm{N}-\mathrm{C}$ (Figure 2c), three new bands at 618, 802, and $1280 \mathrm{~cm}^{-1}$ can be respectively attributed to $\mathrm{C}-\mathrm{S}$ stretching, ring breathing (main-chain hexahydric-ring), and $\mathrm{C}=\mathrm{N}$ symmetric stretching modes. ${ }^{52}$, 53 The observation of $\mathrm{C}-\mathrm{S}$ bonds confirmed that the $\mathrm{S}$ was bonded with $\mathrm{S} / \mathrm{N}-\mathrm{C}$, which can afford a superior reversible capacity. ${ }^{54}$ The content of $\mathrm{WS}_{2}$ in the $\mathrm{WS}_{2} @ \mathrm{~S} / \mathrm{N}-\mathrm{C}$ sample from room temperature to $800{ }^{\circ} \mathrm{C}$ in air was confirmed by TGA analysis (Figure 2d). A weight loss of $14.5 \%$ was observed for pure $\mathrm{WS}_{2}$ due to the oxidation of $\mathrm{WS}_{2}$ into $\mathrm{WO}_{3}$. The weight loss $(57.5 \%)$ for the $\mathrm{WS}_{2} @ \mathrm{~S} / \mathrm{N}-\mathrm{C}$ sample is associated with the combination of oxidation of $\mathrm{WS}_{2}$ and combustion of S/N-C. The content of $\mathrm{WS}_{2}$ in the $\mathrm{WS}_{2} @ \mathrm{~S} / \mathrm{N}-\mathrm{C}$ sample was calculated to be $45.4 \mathrm{wt} \%$. Moreover, Based on the nitrogen adsorption and desorption isotherms, the Brunauer-Emmett-Teller (BET) surface areas of $\mathrm{WS}_{2}$ and $\mathrm{WS}_{2} @ \mathrm{~S} / \mathrm{N}-\mathrm{C}$ samples were found to be 17.74 and $23.4 \mathrm{~m}^{2} \mathrm{~g}^{-1}$, as shown in Figure S2. Furthermore, S/N-C nanofibers were also characterized by XRD, SEM, TEM, HRTEM, as shown in Figure S3a-d. XRD pattern in Figure S3a indicates S/N-C sample is typical carbon material, without other impurities. The sample in SEM and TEM images (Figure S3b and c) shows porous nanofibers with a length of several tens of micrometers. The amorphous nature of S/N-C sample is confirmed by HR-TEM image in Figure S3d. In addition, the content of sulfur doping in the carbon of $\mathrm{WS}_{2} @ \mathrm{~S} / \mathrm{N}-\mathrm{C}$ and $\mathrm{S} / \mathrm{N}-\mathrm{C}$ samples is confirmed to be $\sim 4.8 \%$ and $\sim 6 \%$ by EDS (Figure S4), respectively. 

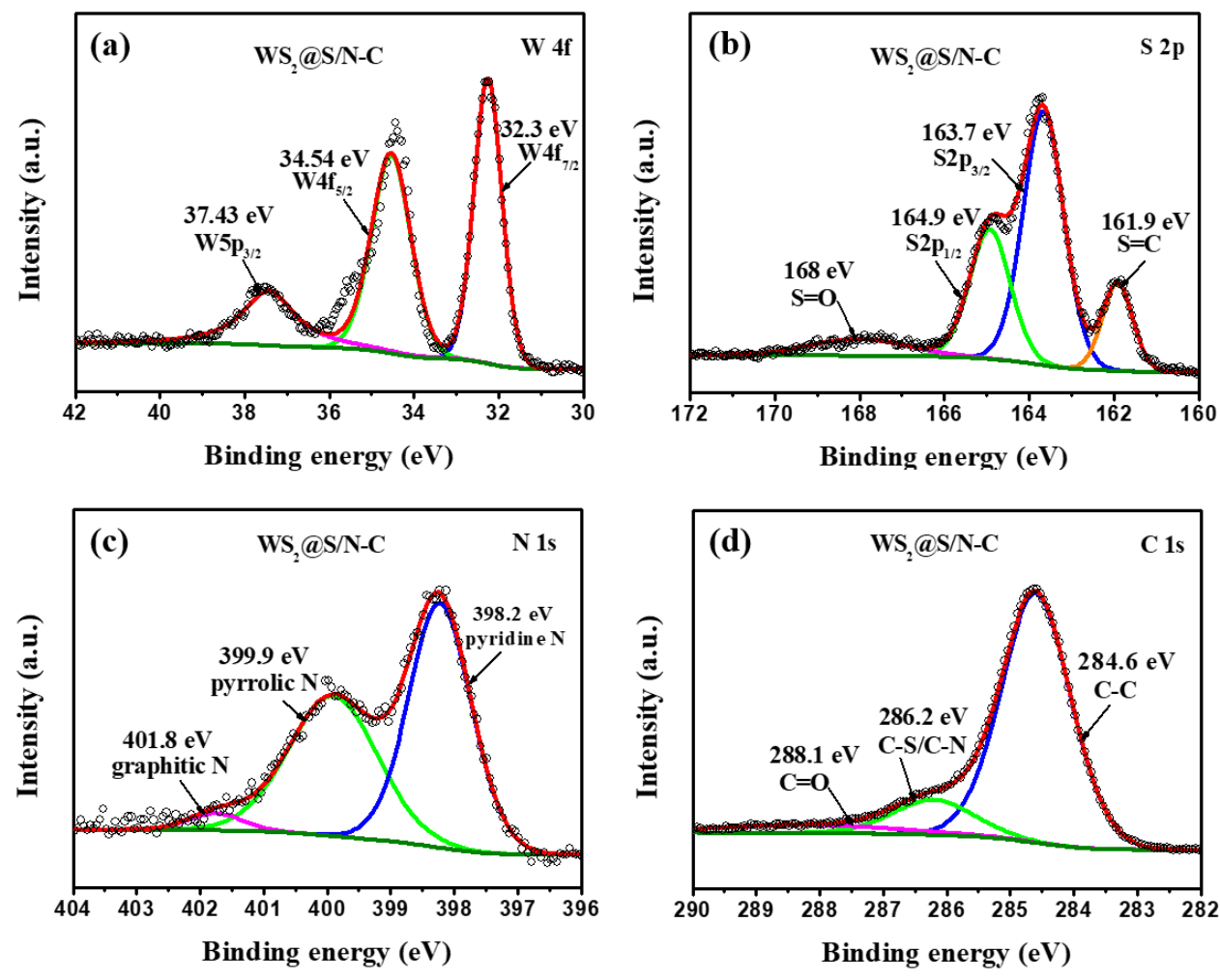

Figure 3 High-resolution XPS spectra of WS $\mathrm{W}_{2} @ \mathrm{~S} / \mathrm{N}-\mathrm{C}$ : (a) W; (b) S; (c) N; (d) C.

The chemical status of the $\mathrm{WS}_{2} @ \mathrm{~S} / \mathrm{N}-\mathrm{C}$ and $\mathrm{WS}_{2}$ samples was characterized by XPS (Figure S5a). Compared to the spectrum of pure $\mathrm{WS}_{2}$, the spectrum of $\mathrm{WS}_{2} @ \mathrm{~S} / \mathrm{N}-\mathrm{C}$ reveals extra distinctive $\mathrm{C}$ and $\mathrm{N}$ peaks, which demonstrate successful doping in accordance with its FTIR spectrum. For WS ${ }_{2} @ \mathrm{~S} / \mathrm{N}-\mathrm{C}$, there are three strong peaks from W centered at 32.3, 34.54, and $37.43 \mathrm{eV}$, as shown in Figure 3a, which exhibit a shift to lower energy than for pure $\mathrm{WS}_{2}$, the peaks of which are located at 33.1, 35.3, and $38.7 \mathrm{eV}$ (Figure S5b), which might be associated with the interaction between $\mathrm{WS}_{2}$ and $\mathrm{C}, \mathrm{N}$. There are two major peaks from $\mathrm{S}$ centered at 162.7 and $163.9 \mathrm{eV}$ in pure $\mathrm{WS}_{2}$ (Figure S5c), slightly shifted to lower energy than for the S peaks $(163.7$ and $164.9 \mathrm{eV})$ of $\mathrm{WS}_{2} @ \mathrm{~S} / \mathrm{N}-\mathrm{C}$ (Figure 3b). Moreover, two shoulder peaks at 161.9 and $168.0 \mathrm{eV}$ in Figure 3b are associated with $\mathrm{S}=\mathrm{C}$ and $\mathrm{S}-\mathrm{O}$ bonds in carbon nanofibers, indicating that $\mathrm{S}$ was successfully incorporated into the carbon matrix. Furthermore, there are three peaks at 398.2, 399.9, and $401.8 \mathrm{eV}$ in the $\mathrm{N}$ 1s spectrum of $\mathrm{WS}_{2} @ \mathrm{~S} / \mathrm{N}-\mathrm{C}$ (Figure 3c) indicate the existence of pyridinic, pyrrolic, and graphitic nitrogen in $\mathrm{WS}_{2} @ \mathrm{~S} / \mathrm{N}-\mathrm{C}$, respectively. ${ }^{55}$ The pyrrolic and pyridinic nitrogen can give rise to surface defects in carbon structures that can offer channels to facilitate $\mathrm{Na}^{+}$diffusion. ${ }^{5}$ In Figure 3d, the $\mathrm{C}$ 1s spectrum can be fitted into three peaks 
for carbon atoms, including for C-C bonds $(284.6 \mathrm{eV}), \mathrm{C}-\mathrm{S} / \mathrm{C}-\mathrm{N}$ bonds $(286.2 \mathrm{eV})$, and $\mathrm{C}=\mathrm{O}$ bonds $(288.1 \mathrm{eV})$. In consequence, it is clear that the nitrogen and sulfur dual-doping allows the $\mathrm{Na}^{+}$ions and electrons to achieve high transfer rates for good performance. ${ }^{56}$
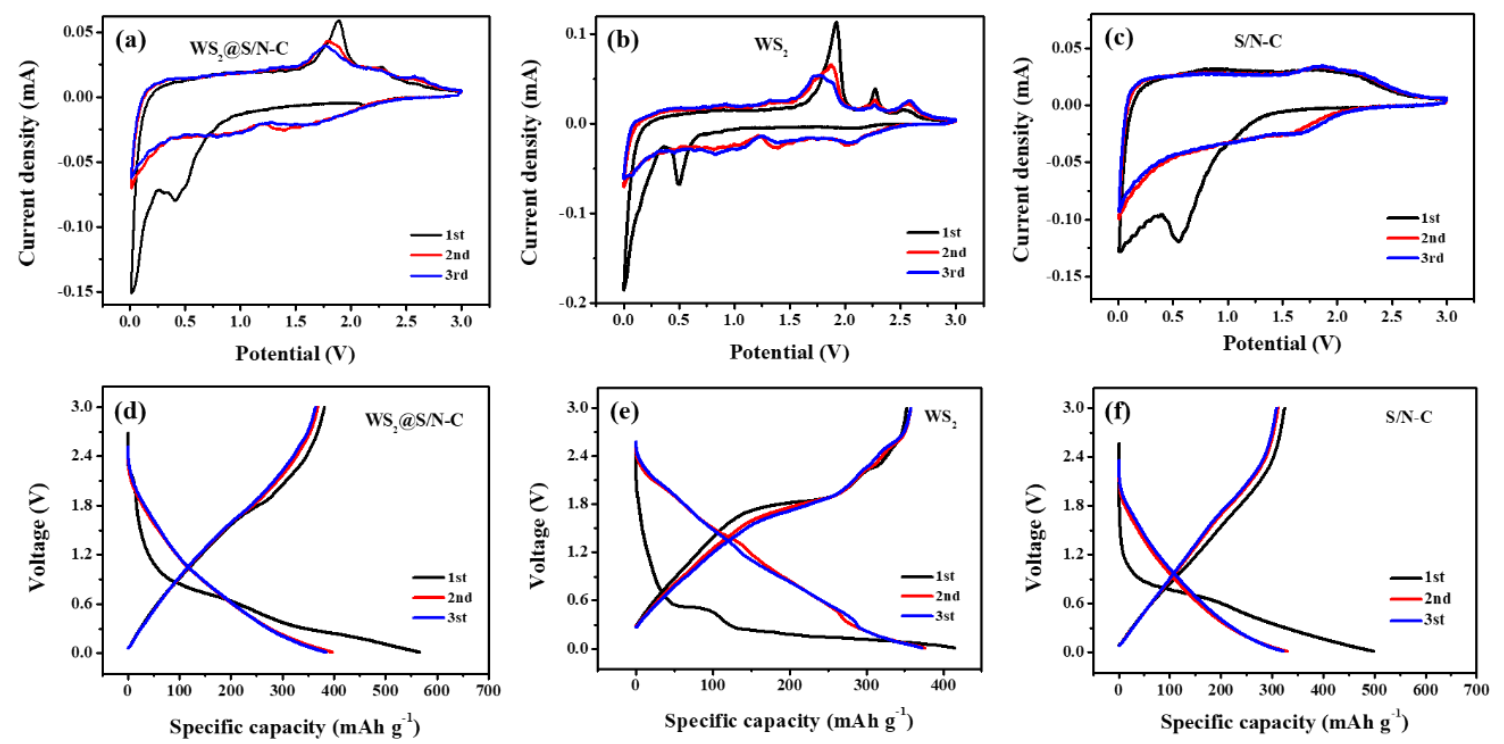

Figure $4 \mathrm{CV}$ curves of (a) $\mathrm{WS}_{2} @ \mathrm{~S} / \mathrm{N}-\mathrm{C}$, (b) $\mathrm{WS}_{2}$ and (c) $\mathrm{S} / \mathrm{N}-\mathrm{C}$ electrodes in the voltage range of 0.01-3 V at a scan rate of $0.1 \mathrm{mV} \mathrm{s}^{-1}$; Charge-discharge profiles of (d) $\mathrm{WS}_{2} @ \mathrm{~S} / \mathrm{N}-\mathrm{C}$, (e) pure $\mathrm{WS}_{2}$ and (f) S/N-C electrodes at a current density of $0.1 \mathrm{Ag}^{-1}$.

The electrochemical properties of the $\mathrm{WS}_{2} @ \mathrm{~S} / \mathrm{N}-\mathrm{C}, \mathrm{WS}_{2}$ and $\mathrm{S} / \mathrm{N}-\mathrm{C}$ electrodes were characterized by $\mathrm{CV}$ and galvanostatic charge-discharge cycling. Figure 4a-c display the CV profiles of the $\mathrm{WS}_{2} @ \mathrm{~S} / \mathrm{N}-\mathrm{C}$ nanofibers, pure $\mathrm{WS}_{2}$ and $\mathrm{S} / \mathrm{N}-\mathrm{C}$ nanofibers for the initial 3 cycles at a scan rate of $0.1 \mathrm{~m} \mathrm{Vs}^{-1}$, respectively. For the $\mathrm{WS}_{2} @ \mathrm{~S} / \mathrm{N}-\mathrm{C}$ electrode, the reduction peak centered at $0.5 \mathrm{~V}$ in the first cycle is attributed to the conversion reaction $\left(\mathrm{WS}_{2}+4 \mathrm{Na}^{+}+4 \mathrm{e}^{-} \rightarrow \mathrm{W}+\right.$ $2 \mathrm{Na}_{2} \mathrm{~S}$ ) and the formation of an irreversible solid electrolyte interphase (SEI) film. In the following cycles, the reduction peak at $\sim 0.5 \mathrm{~V}$ disappears while new reduction peaks appear in the potential range from 1.2 to $1.5 \mathrm{~V}$, indicating the presence of reversible conversion mechanism $\left(4 \mathrm{Na}^{+}+\mathrm{WS}_{2}+4 \mathrm{e}^{-} \rightarrow \mathrm{W}+2 \mathrm{Na}_{2} \mathrm{~S}\right)$. In the anodic scans, three peaks located at $1.8,2.2$, and $2.5 \mathrm{~V}$ are corresponded to the oxidation of $\mathrm{W}$ to $\mathrm{WS}_{2}$ during the desodiation process. ${ }^{33}$ Compared with the $\mathrm{WS}_{2} @ \mathrm{~S} / \mathrm{N}-\mathrm{C}$ electrode, similar reduction and oxidation peaks were also observed for pure $\mathrm{WS}_{2}$, although their variation was different from that of the $\mathrm{WS}_{2} @ \mathrm{~S} / \mathrm{N}-\mathrm{C}$ electrode. For the S/N-C 
electrode, a reduction peak centered at $\sim 0.5 \mathrm{~V}$ in the first cycle is associated with the formation of an irreversible solid electrolyte interphase (SEI) film. The reduction and oxidation peaks of the $\mathrm{WS}_{2} @ \mathrm{~S} / \mathrm{N}-\mathrm{C}$ and S/N-C electrodes show a much more stable profile and tend to overlap each other in the following two cycles, indicating faster $\mathrm{Na}^{+}$ion insertion/extraction kinetics and higher reversibility of the electrode reactions for $\mathrm{WS}_{2} @ \mathrm{~S} / \mathrm{N}-\mathrm{C}$ and $\mathrm{S} / \mathrm{N}-\mathrm{C}$ electrodes. This confirmed the $\mathrm{S} / \mathrm{N}-\mathrm{C}$ nanofibers could stabilize the $\mathrm{WS}_{2}$ during the electrochemical process. The charge/discharge curves of the $\mathrm{WS}_{2} @ \mathrm{~S} / \mathrm{N}-\mathrm{C}$ nanofibers, pure $\mathrm{WS}_{2}$ and $\mathrm{S} / \mathrm{N}-\mathrm{C}$ nanofibers in Figure 4d-f were collected at $0.1 \mathrm{Ag}^{-1}$. The $\mathrm{WS}_{2} @ \mathrm{~S} / \mathrm{N}-\mathrm{C}$ nanofibers delivered a discharge and charge capacity of 566 and $381 \mathrm{~mA} \mathrm{~h} \mathrm{~g}^{-1}$ while pure $\mathrm{WS}_{2}\left(416\right.$ and $352 \mathrm{~mA} \mathrm{~h} \mathrm{~g}^{-1}$ ) and S/N-C nanofibers (465.8 and $356.9 \mathrm{~mA} \mathrm{~h} \mathrm{~g}^{-1}$ ), respectively. Moreover, the coincidence of subsequent discharge/charge curves for pure $\mathrm{WS}_{2} @ \mathrm{~S} / \mathrm{N}-\mathrm{C}$, indicating a reversible and stable electrochemical performance.
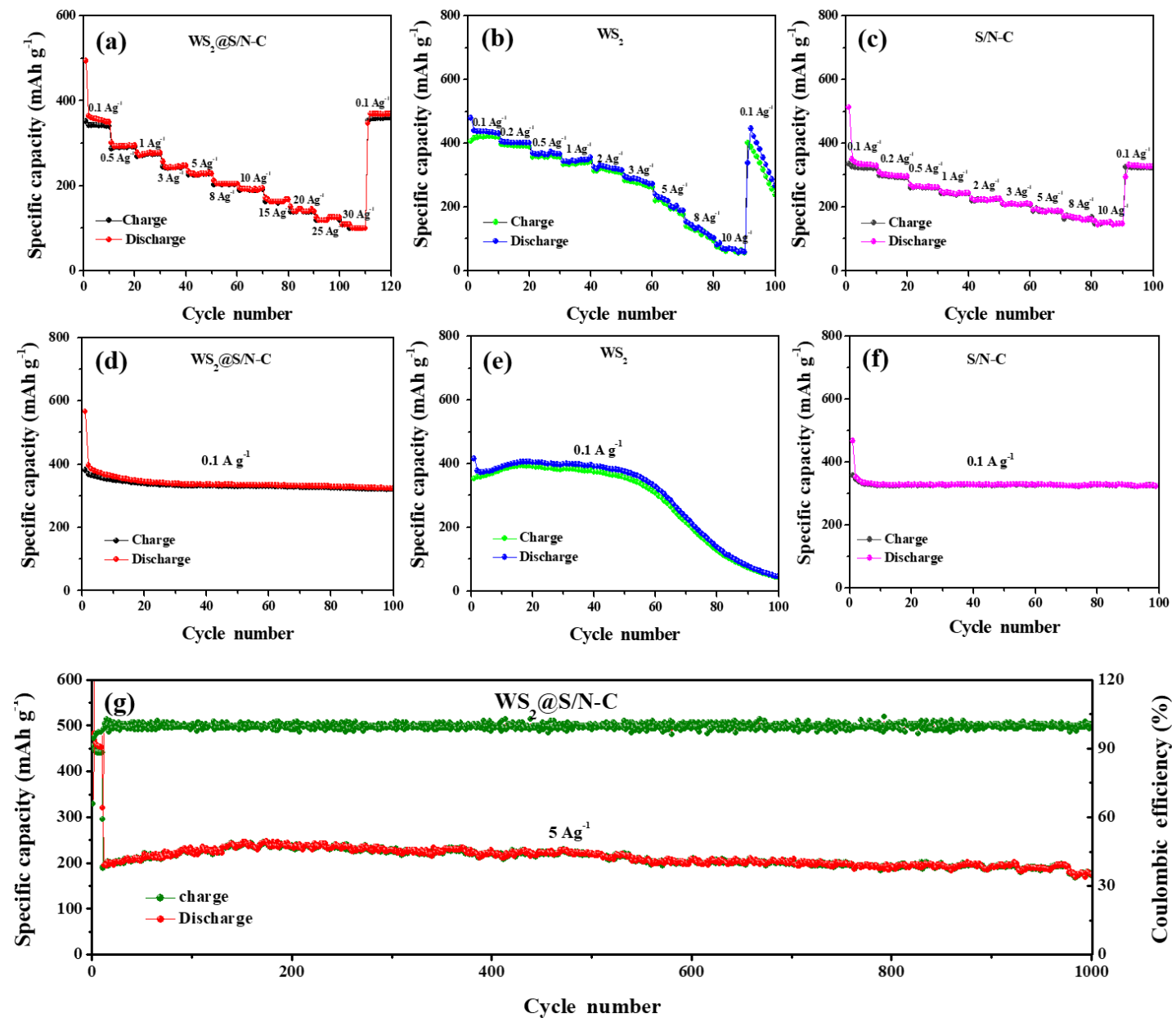

Figure 5 Rate capability of the (a) $\mathrm{WS}_{2} @ \mathrm{~S} / \mathrm{N}-\mathrm{C}$, (b) $\mathrm{WS}_{2}$ and (c) $\mathrm{S} / \mathrm{N}-\mathrm{C}$ electrodes at various current densities; Cycling performance of the (d) WS $\mathrm{W}_{2} @ \mathrm{~S} / \mathrm{N}-\mathrm{C}$, (e) $\mathrm{WS}_{2}$ and (f) $\mathrm{S} / \mathrm{N}-\mathrm{C}$ electrodes 
at a current density of $0.1 \mathrm{~A} \mathrm{~g} \mathrm{~g}^{-1}$; (g) Long-term cycling performance and Coulombic efficiency of $\mathrm{WS}_{2} @ \mathrm{~S} / \mathrm{N}-\mathrm{C}$ electrode at a current density of $5 \mathrm{~A} \mathrm{~g}^{-1}$.

Figure 5a shows the capacity of the $\mathrm{WS}_{2} @ \mathrm{~S} / \mathrm{N}-\mathrm{C}$ electrode at various current densities from 0.1 to $30 \mathrm{~A} \mathrm{~g}^{-1}$. The electrode delivers a reversible capacity of $371,291,275,246,230,204,192,167$, 145 , and $125 \mathrm{~mA} \mathrm{~h} \mathrm{~g}^{-1}$ at current density of $0.1,0.5,1,3,5,8,10,15,20$, and $25 \mathrm{~A} \mathrm{~g}^{-1}$, respectively. Even at a very high current density of $30 \mathrm{~A} \mathrm{~g}^{-1}$, it still delivers capacity of $108 \mathrm{~mA} \mathrm{~h}$ $\mathrm{g}^{-1}$ and when the current density returns to $0.1 \mathrm{~A} \mathrm{~g}^{-1}$, it keeps a reversible capacity of $360 \mathrm{~mA} \mathrm{~h} \mathrm{~g}^{-1}$. The pure $\mathrm{WS}_{2}$ electrode and S/N-C electrodes (Figure 5b and c), however, exhibits much poorer rate performance. The reversible capacity for the pure $\mathrm{WS}_{2}$ electrode rapidly declines to $237 \mathrm{~mA} \mathrm{~h}$ $\mathrm{g}^{-1}$ when the current density returns to $0.1 \mathrm{~A} \mathrm{~g}^{-1}$. The $\mathrm{S} / \mathrm{N}-\mathrm{C}$ electrode could keep a reversible capacity of $322.2 \mathrm{~mA} \mathrm{~h} \mathrm{~g}^{-1}$, which is obviously lower than that of $\mathrm{WS}_{2} @ \mathrm{~S} / \mathrm{N}-\mathrm{C}$ electrode. The excellent rate performance of $\mathrm{WS}_{2} @ \mathrm{~S} / \mathrm{N}-\mathrm{C}$ can be attributed to its structure. The lotus rhizome-like carbon nanofibers could offer short paths to facilitate electron transfer, prevent pulverization of the electrode structure, and offer convenient $\mathrm{Na}^{+}$transport. Electrochemical impedance spectroscopy (EIS) was also carried out to study the reaction kinetics of $\mathrm{WS}_{2} @ \mathrm{~S} / \mathrm{N}-\mathrm{C}$ and pure $\mathrm{WS}_{2}$ electrode cycling after for 1 cycles at $0.1 \mathrm{~A} \mathrm{~g}^{-1}$. In Figure S6, the WS $\mathrm{W}_{2} @ \mathrm{~S} / \mathrm{N}-\mathrm{C}$ electrode exhibits a much lower charge transfer resistance $\left(\mathrm{R}_{\mathrm{ct}}, 298 \Omega\right)$ than the pure $\mathrm{WS}_{2}$ electrode (2129 $\Omega$ ), based on the equivalent circuit simulation, which implies facile charge transfer at the electrode/electrolyte interface. Moreover, the discharge capacity of $\mathrm{WS}_{2} @ \mathrm{~S} / \mathrm{N}-\mathrm{C}$ reached $319 \mathrm{mAh} \cdot \mathrm{g}^{-1}$ at $0.1 \mathrm{~A} \mathrm{~g}^{-1}$ after 100 cycles (Figure 5d), showing good cycling stability. In comparison, the pure $\mathrm{WS}_{2}$ only possessed $43 \mathrm{~mA} \mathrm{~h} \cdot \mathrm{g}^{-1}$ after 100 cycles (Figure 5e). The $\mathrm{S} / \mathrm{N}-\mathrm{C}$ can sustain $315 \mathrm{~mA} \mathrm{~h} \mathrm{~g}^{-1}$ after 100 cycles with good stability (Figure 5f). This demonstrates that $\mathrm{S} / \mathrm{N}-\mathrm{C}$ nanofibers facilitated the stability of $\mathrm{WS}_{2}$. To further explain the difference in cycling stability between the two kinds of electrodes, the morphologies of cycled $\mathrm{WS}_{2} @ \mathrm{~S} / \mathrm{N}-\mathrm{C}$ and pure $\mathrm{WS}_{2}$ were characterized by SEM, as shown in Figure S7. Obviously, compared with fresh $\mathrm{WS}_{2} @ \mathrm{~S} / \mathrm{N}-\mathrm{C}$ electrode, the surface of this electrode cycled after 100 cycles became less smooth due to the formation of solid electrolyte interphase (SEI). Although some small particles emerged, the rod-like morphology was partially maintained. On the contrary, the morphology of the $\mathrm{WS}_{2}$ electrode cycled after 100 cycles changed significantly. No nanosheets could be observed. Based on above results, it was revealed that the different structural stabilities led to the different cycling 
stabilities. Moreover, the $\mathrm{WS}_{2} @ \mathrm{~S} / \mathrm{N}-\mathrm{C}$ even exhibited a capacity of $174 \mathrm{~mA} \mathrm{~h} \cdot \mathrm{g}^{-1}$ at a current of 5 $\mathrm{A} \mathrm{g}^{-1}$ over 1000 cycles, with capacity retention of $89 \%$, demonstrating excellent ultra-long cycling stability (Figure 5g).
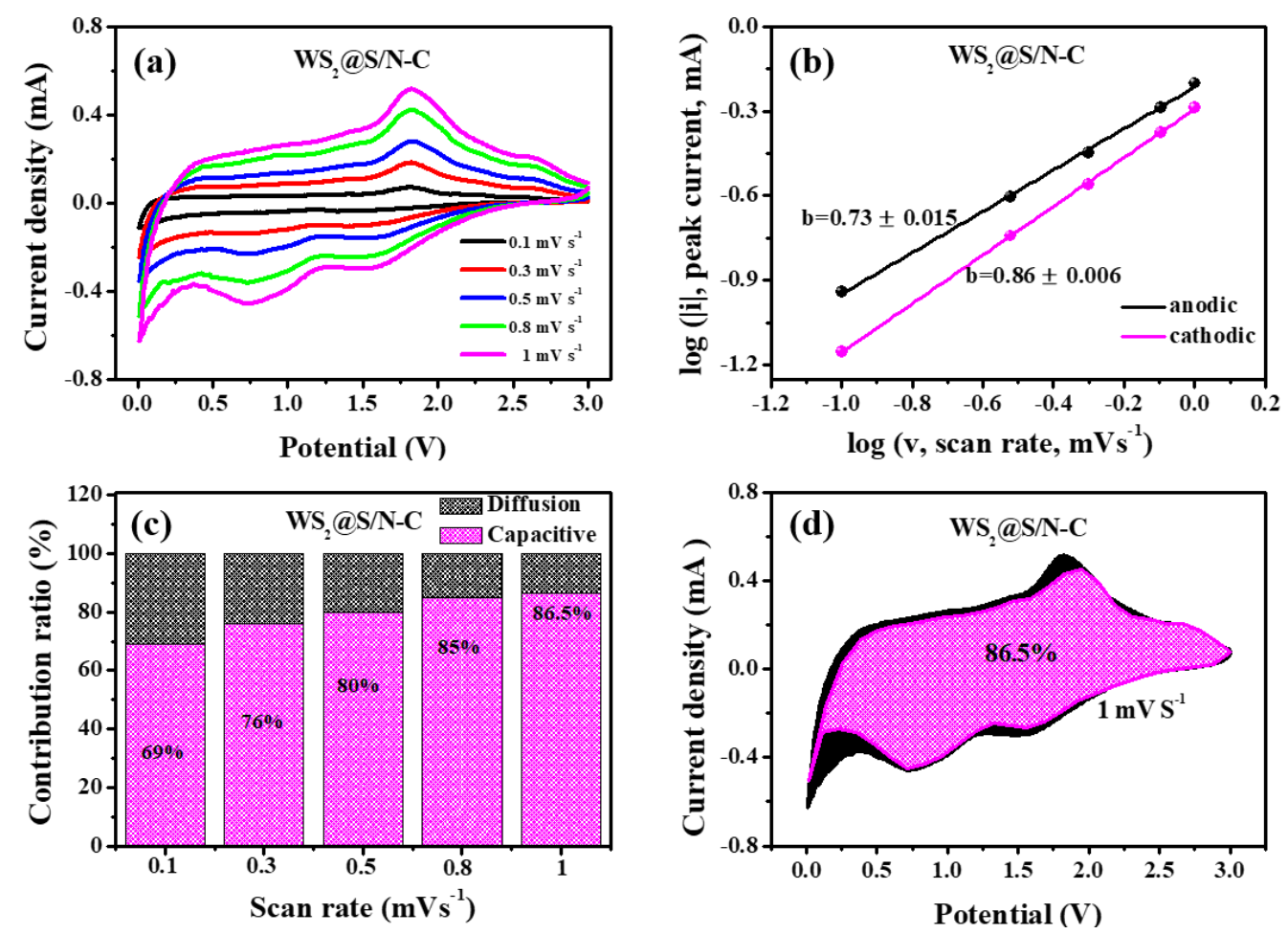

Figure 6 (a) CV curves of $\mathrm{WS}_{2} @ \mathrm{~S} / \mathrm{N}-\mathrm{C}$ electrodes at different scan rates; (b) $\log i$ vs. $\log v$ plots of WS $\mathrm{W}_{2} @ \mathrm{~S} / \mathrm{N}-\mathrm{C}$ electrodes; (c) Ratio of diffusion and capacitive contributions to the capacity at various scan rates for $\mathrm{WS}_{2} @ \mathrm{~S} / \mathrm{N}-\mathrm{C}$ electrodes; (d) Capacitive charge storage contribution (pink region) for $\mathrm{WS}_{2} @ \mathrm{~S} / \mathrm{N}-\mathrm{C}$ electrode at $1.0 \mathrm{mV} \mathrm{s}^{-1}$.

To further evaluate the electrochemical performance of $\mathrm{WS}_{2} @ \mathrm{~S} / \mathrm{N}-\mathrm{C}$ anode, CV measurements at a series of scan rates from $0.1 \mathrm{mV} \mathrm{s}^{-1}$ to $1 \mathrm{mV} \mathrm{s}^{-1}$ were carried out. As displayed in Figure 6a, with the scan rates increasing, all the CV curves retained similar shapes with only a small deviation of the redox peaks, suggesting high rate capability and small potential polarization. As is well known, the electrochemical capacity is contributed by two mechanisms, the faradaic charge transfer process (ion diffusion) and the non-faradaic contribution (pseudocapacitance). ${ }^{57}$ The relationship between peak current and scan rate can indicate the contribution of each part, as follows: ${ }^{58}$ 


$$
i=a v^{b}(1)
$$

and

$$
\log i=b \log v+\log a(2)
$$

where $i$ represents the peak current, $v$ is the scan rate, and $a$ and $b$ are adjustment parameters, respectively. The $b$ value reveals the different types of charge storage. The values of 0.5 and 1 represent the faradaic charge transfer process and the non-faradaic contribution, respectively. In Figure $6 \mathbf{b}$, the $b$ values of $\mathrm{WS}_{2} @ \mathrm{~S} / \mathrm{N}-\mathrm{C}$ anode were calculated to be $0.73 \pm 0.015$ for the anodic peaks and $0.86 \pm 0.006$ for the cathodic peaks, suggesting that the sodium storage reaction of $\mathrm{WS}_{2} @ \mathrm{~S} / \mathrm{N}-\mathrm{C}$ anode was determined by both pseudocapacitive behavior and ion diffusion control. The percent contributions of the two parts at a serious of scan rates can be calculated from the following equation:

$$
i=k_{l} v+k_{2} v^{l / 2}(3)
$$

where $k_{1} v$ represents the pseudocapacitive part and $k_{2} v^{1 / 2}$ represents the ion diffusion part. As can be seen from Figure 6c, the pseudocapacitive contribution increased from $69 \%$ to $86.5 \%$ as the scan rate increased from $0.1 \mathrm{mV} \mathrm{s}^{-1}$ to $1 \mathrm{mV} \mathrm{s}^{-1}$. The detailed pseudocapacitive fraction at $1 \mathrm{mV} \mathrm{s}^{-1}$ is also illustrated in Figure 6d. These results mean that the pseudocapacitive contribution plays the major role in the overall capacity of the $\mathrm{WS}_{2} @ \mathrm{~S} / \mathrm{N}-\mathrm{C}$ anode. This might be ascribed to the effect of S/N-C since there are more redox reactions in the surface of S/N-C. ${ }^{5}$ 
a)
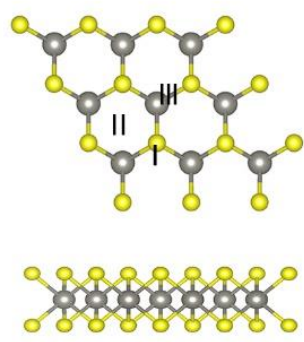

c)
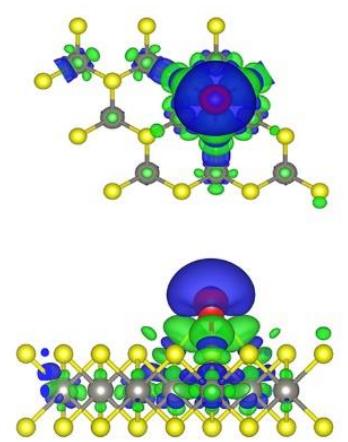

b)
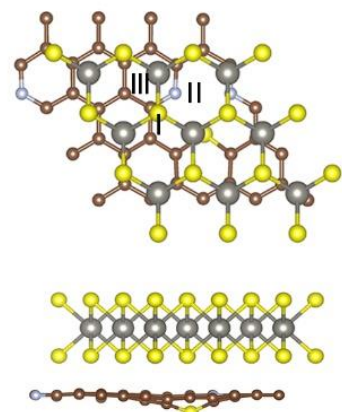

d)
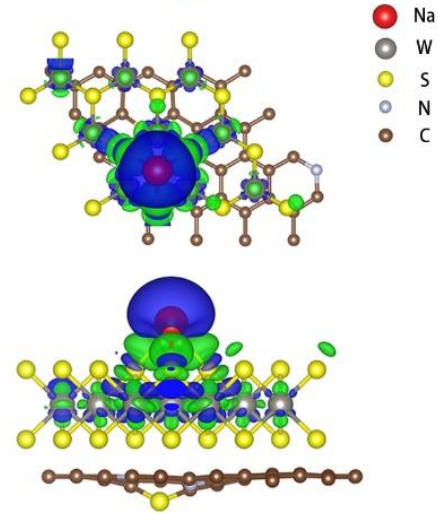

Figure 7 Adsorption sites for of I, II and III Na on (a) pure $\mathrm{WS}_{2}$ and (b) the $\mathrm{WS}_{2}$ in $\mathrm{WS}_{2} @ \mathrm{~S} / \mathrm{N}-\mathrm{C}$; Differences of charge density (charge accumulation: green, charge depletion: blue) with an isosurface level of $0.001 \mathrm{e} / \AA^{3}$ for Na on (c) pure $\mathrm{WS}_{2}$ and (d) the $\mathrm{WS}_{2}$ in $\mathrm{WS}_{2} @ \mathrm{~S} / \mathrm{N}-\mathrm{C}$ in the most stable adsorption configuration.

To obtain theoretical support for the results, we studied the $\mathrm{Na}^{+}$adsorption behavior on both pristine WS $\mathrm{W}_{2}$ surface and $\mathrm{WS}_{2} @ \mathrm{~S} / \mathrm{N}-\mathrm{C}$ surface by DFT calculations. According to the previous theoretical calculations, the $\mathrm{S} / \mathrm{N}$ co-doped graphene model can be as the $\mathrm{S} / \mathrm{N}$ co-doped carbon nanofiber to analyze the adsorption behavior for the $\mathrm{Li}^{+}, \mathrm{Na}^{+}$and $\mathrm{K}^{+} .5$, 59-63 Thus, we designed the heterostructure of $\mathrm{WS}_{2}$ and $\mathrm{S} / \mathrm{N}$ co-doped graphene to investigate the synergistic effects for $\mathrm{Na}$ adsorption. As shown in Figure 7a and b, both the pristine $\mathrm{WS}_{2}$ and $\mathrm{WS}_{2} @ \mathrm{~S} / \mathrm{N}-\mathrm{C}$ have three adsorption sites of S-top ( I ), hollow ( II ) and W-top (III), respectively. And the adsorption energies of $\mathrm{Na}$ atom adsorption on pristine $\mathrm{WS}_{2}$ and $\mathrm{WS}_{2} @ \mathrm{~S} / \mathrm{N}-\mathrm{C}$ were calculated and illustrated in Tables $\mathbf{S 1}$ and $\mathbf{S 2}$. For the S-top site, the adsorption energy of the $\mathrm{Na}$ in $\mathrm{WS}_{2} @ \mathrm{~S} / \mathrm{N}-\mathrm{C}$ was $-0.897 \mathrm{eV}$ that was lower than that in pristine $\mathrm{WS}_{2}(-0.494 \mathrm{eV})$. After the $\mathrm{Na}$ adsorption on the hollow site of pristine $\mathrm{WS}_{2}$ and $\mathrm{WS}_{2} @ \mathrm{~S} / \mathrm{N}-\mathrm{C}$, the adsorption energies are of $-0.744 \mathrm{eV}$ and -1.168 eV, respectively. Clearly, the W-top site on $\mathrm{WS}_{2} @ \mathrm{~S} / \mathrm{N}-\mathrm{C}$ has the smaller adsorption energy of $-1.208 \mathrm{eV}$ than that of pristine $\mathrm{WS}_{2}(-0.759 \mathrm{eV})$. The smaller adsorption energies of $\mathrm{Na}$ adsorption on $\mathrm{WS}_{2} @ \mathrm{~S} / \mathrm{N}-\mathrm{C}$ than that of pristine $\mathrm{WS}_{2}$, indicating that $\mathrm{WS}_{2} @ \mathrm{~S} / \mathrm{N}-\mathrm{C}$ is helpful for Na storage. 
Moreover, we calculated the three-dimensional charge density difference to understand the mechanism of charge transfer on W-top site of pristine $\mathrm{WS}_{2}$ or $\mathrm{WS}_{2} @ \mathrm{~S} / \mathrm{N}-\mathrm{C}$ with a Na atom. As shown in Figure 7c, the charge accumulation is found on the $\mathrm{W}$ atoms, and the charge depletion appears on the $\mathrm{Na}$ ion at the same time. The results demonstrate that the charge has accumulated much more massively on the $\mathrm{WS}_{2} @ \mathrm{~S} / \mathrm{N}-\mathrm{C}$ (Figure 7d) than on the pristine $\mathrm{WS}_{2}$ (Figure 7c), which can be verified by the Bader charges. According to Bader charge analysis, $0.79 \mathrm{e}$ of the $\mathrm{Na}$ atom is transferred onto the $\mathrm{WS}_{2} @ \mathrm{~S} / \mathrm{N}-\mathrm{C}$ (Table S2), while only 0.76 e of the Na atom for the pristine $\mathrm{WS}_{2}$ (Table S1). This shows that $\mathrm{S} / \mathrm{N}-\mathrm{C}$ could trap more $\mathrm{Na}$ atoms due to increasing the adsorption energy of the $\mathrm{Na}$ atom.

\section{Conclusion}

In conclusion, we have successfully realized the incorporation of $\mathrm{WS}_{2}$ nanosheets into carbon nanofibers via an electrospinning/sulfidation process. Compared to pure $\mathrm{WS}_{2}$, the $\mathrm{WS}_{2} @ \mathrm{~S} / \mathrm{N}-\mathrm{C}$ nanofibers exhibit a higher rate capacity of $108 \mathrm{~mA} \mathrm{~h} \mathrm{~g}^{-1}$ at $30 \mathrm{~A} \mathrm{~g}^{-1}$ and a stable capacity of 174 $\mathrm{mA} \mathrm{h} \mathrm{g}{ }^{-1}$ at $5 \mathrm{~A} \mathrm{~g}^{-1}$ after 1000 cycles. The theoretical studies demonstrate that S/N-C nanofibers effectively facilitate the storage of $\mathrm{Na}$ on $\mathrm{WS}_{2}$. Moreover, analysis of the sodium storage mechanism has demonstrated that the capacitive contribution plays the dominant role in the whole capacity contribution owing to the $\mathrm{S} / \mathrm{N}$-heteroatom doping and the existence of the mesoporous defect-rich structure in the S/N-C matrix.

\section{Conflicts of interest}

There are no conflicts to declare.

\section{Acknowledgements}

The work was financially supported by an Australian Research Council (ARC) Linkage Project (DP160102627, DE170100928). We also thank Dr Tania Silver (University of Wollongong) for revising the manuscript.

\section{References}


1. Yabuuchi, N.; Kubota, K.; Dahbi, M.; Komaba, S., Research development on sodium-ion batteries. Chem. Rev. 2014, 114 (23), 11636-82.

2. Christoph Vaalma, D. B., Marcel Weil and Stefano Passerini, A cost and resource analysis of sodium-ion batteries. Nature Rev. Mater. 2018, 3, 18013.

3. Fang, Y.; Yu, X.-Y.; Lou, X. W., Nanostructured electrode materials for advanced sodium-ion batteries. Matter 2019, 1 (1), 90-114.

4. Nayak, P. K.; Yang, L.; Brehm, W.; Adelhelm, P., From lithium-ion to sodium-ion batteries: advantages, challenges, and surprises. Angew. Chem. Int. Ed. 2018, 57 (1), 102-120.

5. Li, X.; Hu, X.; Zhou, L.; Wen, R.; Xu, X.; Chou, S.; Chen, L.; Cao, A.-M.; Dou, S., A S/N-doped high-capacity mesoporous carbon anode for Na-ion batteries. J. Mater. Chem. A 2019, 7 (19), 11976-11984.

6. Cao, Y.; Xiao, L.; Sushko, M. L.; Wang, W.; Schwenzer, B.; Xiao, J.; Nie, Z.; Saraf, L. V.; Yang, Z.; Liu, J., Sodium ion insertion in hollow carbon nanowires for battery applications. Nano Lett. 2012, 12 (7), 3783-3787.

7. Hou, H.; Banks, C. E.; Jing, M.; Zhang, Y.; Ji, X., Carbon quantum dots and their derivative 3D porous carbon frameworks for sodium-ion batteries with ultralong cycle life. Adv. Mater. 2015, 27 (47), 7861-7866.

8. Lu, P.; Sun, Y.; Xiang, H.; Liang, X.; Yu, Y., 3D Amorphous carbon with controlled porous and disordered structures as a high-rate anode material for sodium-ion batteries. Adv. Energy Mater. 2018, 8 (8) 1702434.

9. Ma, W.; Wang, J.; Gao, H.; Niu, J.; Luo, F.; Peng, Z.; Zhang, Z., A mesoporous antimony-based nanocomposite for advanced sodium ion batteries. Energy Stor. Mater. 2018, 13, 247-256.

10. Sheng, M.; Zhang, F.; Ji, B.; Tong, X.; Tang, Y., A Novel tin-graphite dual-ion battery based on sodium-ion electrolyte with high energy density. Adv. Energy Mater. 2017, 7 (7), 1601963.

11. Yang, H.; Xu, R.; Yao, Y.; Ye, S.; Zhou, X.; Yu, Y., Multicore-shell Bi@N-doped carbon nanospheres for high power density and long cycle life sodium- and potassium-ion anodes. Adv. Funct. Mater. 2019, 29 (13) 1809195.

12. Zhao, Y.; Manthiram, A., High-capacity, high-rate Bi-Sb alloy anodes for lithium-ion and sodium-ion batteries. Chem. Mater. 2015, 27 (8), 3096-3101.

13. Chen, C.; Wen, Y.; Hu, X.; Ji, X.; Yan, M.; Mai, L.; Hu, P.; Shan, B.; Huang, Y., $\mathrm{Na}^{+}$ intercalation pseudocapacitance in graphene-coupled titanium oxide enabling ultra-fast sodium storage and long-term cycling. Nature Commun. 2015, 6, 6929.

14. Zheng, Y.; Zhou, T.; Zhang, C.; Mao, J.; Liu, H.; Guo, Z., Boosted charge transfer in $\mathrm{SnS} / \mathrm{SnO}_{2}$ heterostructures: Toward high rate capability for sodium-ion batteries. Angew. Chem. Int. Ed. 2016, 55 (10), 3408-13.

15. Chen, D.; Peng, L.; Yuan, Y.; Zhu, Y.; Fang, Z.; Yan, C.; Chen, G.; Shahbazian-Yassar, R.; Lu, J.; Amine, K.; Yu, G., Two-dimensional holey $\mathrm{Co}_{3} \mathrm{O}_{4}$ nanosheets for high-rate alkali-ion batteries: From rational synthesis to in situ probing. Nano Lett. 2017, 17 (6), 3907-3913.

16. Zhang, K.; Park, M.; Zhou, L.; Lee, G.-H.; Li, W.; Kang, Y.-M.; Chen, J., Urchin-like CoSe 2 as a high-performance anode material for sodium-ion batteries. Adv. Funct. Mater. 2016, 26 (37), 6728-6735.

17. Wang, Y.; Wang, Y.; Kang, W.; Cao, D.; Li, C.; Cao, D.; Kang, Z.; Sun, D.; Wang, R.; Cao, Y., 
$\mathrm{TiO}_{2}$-coated interlayer-expanded $\mathrm{MoSe}_{2} /$ phosphorus-doped carbon nanospheres for ultrafast and ultralong cycling sodium storage. Adv. Sci. 2019, 6 (1), 1801222.

18. Zhang, F.; Xia, C.; Zhu, J.; Ahmed, B.; Liang, H.; Velusamy, D. B.; Schwingenschlögl, U.; Alshareef, H. N., $\mathrm{SnSe}_{2} 2 \mathrm{D}$ Anodes for advanced sodium ion batteries. Adv. Energy Mater. 2016, 6 (22) 1601188.

19. Wang, S.; Xia, L.; Yu, L.; Zhang, L.; Wang, H.; Lou, X. W. D., Free-standing nitrogen-doped carbon nanofiber films: integrated electrodes for sodium-ion batteries with ultralong cycle life and superior rate capability. Adv. Energy Mater. 2016, 6 (7) 1502217.

20. Li, W.; Zhou, M.; Li, H.; Wang, K.; Cheng, S.; Jiang, K., A high performance sulfur-doped disordered carbon anode for sodium ion batteries. Energy Environ. Sci. 2015, 8 (10), 2916-2921.

21. Yang, J.; Zhou, X.; Wu, D.; Zhao, X.; Zhou, Z., S-doped N-rich carbon nanosheets with expanded interlayer distance as anode materials for sodium-ion batteries. Adv. Mater. 2017, 29 (6), 1604108.

22. Li, Z.; Ding, J.; Mitlin, D., Tin and tin compounds for sodium ion battery anodes: phase transformations and performance. Acc. Chem. Res. 2015, 48 (6), 1657-1665.

23. Ni, J.; Bi, X.; Jiang, Y.; Li, L.; Lu, J., Bismuth chalcogenide compounds $\mathrm{Bi}_{2} \mathrm{X}_{3}(\mathrm{X}=\mathrm{O}, \mathrm{S}, \mathrm{Se})$ : Applications in electrochemical energy storage. Nano Energy 2017, 34, 356-366.

24. Hu, Z.; Liu, Q.; Chou, S. L.; Dou, S. X., Advances and challenges in metal sulfides/selenides for next-generation rechargeable sodium-ion batteries. Adv. Mater. 2017, 29 (48) 1700606.

25. Yang, D.; Chen, W.; Zhang, X.; Mi, L.; Liu, C.; Chen, L.; Guan, X.; Cao, Y.; Shen, C., Facile and scalable synthesis of low-cost FeS@C as long-cycle anodes for sodium-ion batteries. J. Mater. Chem. A 2019, 7 (34), 19709-19718.

26. Fang, Y.; Yu, X.-Y.; Lou, X. W. D., Bullet-like $\mathrm{Cu}_{9} \mathrm{~S}_{5}$ hollow particles coated with nitrogen-doped carbon for sodium-ion batteries. Angew. Chem. Int. Ed. 2019, 58 (23), 7744-7748.

27. Zhang, Y.; Zhou, Q.; Zhu, J.; Yan, Q.; Dou, S. X.; Sun, W., Nanostructured metal chalcogenides for energy storage and electrocatalysis. Adv. Funct. Mater. 2017, 27 (35), 1702317.

28. Yun, Q.; Lu, Q.; Zhang, X.; Tan, C.; Zhang, H., Three-dimensional architectures constructed from transition-metal dichalcogenide nanomaterials for electrochemical energy storage and conversion. Angew. Chem. Int. Ed. 2018, 57 (3), 626-646.

29. Huang, J.; Wei, Z.; Liao, J.; Ni, W.; Wang, C.; Ma, J., Molybdenum and tungsten chalcogenides for lithium/sodium-ion batteries: Beyond $\mathrm{MoS}_{2}$. J. Energy Chem. 2019, 33, 100-124.

30. Lim, Y. V.; Wang, Y.; Kong, D.; Guo, L.; Wong, J. I.; Ang, L. K.; Yang, H. Y., Cubic-shaped $\mathrm{WS}_{2}$ nanopetals on a prussian blue derived nitrogen-doped carbon nanoporous framework for high performance sodium-ion batteries. J. Mater. Chem. A 2017, 5 (21), 10406-10415.

31. Song, Y.; Liao, J.; Chen, C.; Yang, J.; Chen, J.; Gong, F.; Wang, S.; Xu, Z.; Wu, M., Controllable morphologies and electrochemical performances of self-assembled nano-honeycomb $\mathrm{WS}_{2}$ anodes modified by graphene doping for lithium and sodium ion batteries. Carbon 2019, 142 , 697-706.

32. Wang, Y.; Kong, D.; Huang, S.; Shi, Y.; Ding, M.; Von Lim, Y.; Xu, T.; Chen, F.; Li, X.; Yang, H. Y., 3D carbon foam-supported $\mathrm{WS}_{2}$ nanosheets for cable-shaped flexible sodium ion batteries. $J$. Mater. Chem. A 2018, 6 (23), 10813-10824.

33. Wang, Y.; Kong, D.; Shi, W.; Liu, B.; Sim, G. J.; Ge, Q.; Yang, H. Y., Ice templated free-standing hierarchically $\mathrm{WS}_{2} / \mathrm{CNT}-\mathrm{rGO}$ aerogel for high-performance rechargeable lithium 
and sodium ion batteries. Adv. Energy Mater. 2016, 6 (21) 1601057.

34. Choi, S. H.; Kang, Y. C., Sodium ion storage properties of $\mathrm{WS}_{2}$-decorated three-dimensional reduced graphene oxide microspheres. Nanoscale 2015, 7 (9), 3965-3970.

35. Su, D.; Dou, S.; Wang, G., WS $\mathrm{WS}_{2} @$ graphene nanocomposites as anode materials for Na-ion batteries with enhanced electrochemical performances. Chem. Commun. 2014, 50 (32), 4192-4195.

36. Song, Y.; Bai, S.; Zhu, L.; Zhao, M.; Han, D.; Jiang, S.; Zhou, Y. N., Tuning pseudocapacitance via C-S bonding in $\mathrm{WS}_{2}$ nanorods anchored on $\mathrm{N}, \mathrm{S}$ codoped graphene for high-power lithium batteries. ACS Appl. Mater. Interfaces 2018, 10 (16), 13606-13613.

37. Wang, X.; Huang, J.; Li, J.; Cao, L.; Hao, W.; Xu, Z., Improved Na storage performance with the involvement of nitrogen-doped conductive carbon into $\mathrm{WS}_{2}$ Nanosheets. ACS Appl. Mater. Interfaces 2016, 8 (36), 23899-23908.

38. Zeng, X.; Ding, Z.; Ma, C.; Wu, L.; Liu, J.; Chen, L.; Ivey, D. G.; Wei, W., Hierarchical nanocomposite of hollow N-doped carbon spheres decorated with ultrathin $\mathrm{WS}_{2}$ Nanosheets for high-performance lithium-ion battery anode. ACS Appl. Mater. Interfaces 2016, 8 (29), 18841-18848.

39. Pang, Q.; Gao, Y.; Zhao, Y.; Ju, Y.; Qiu, H.; Wei, Y.; Liu, B.; Zou, B.; Du, F.; Chen, G., Improved lithium-ion and sodium-ion storage properties from few-layered $\mathrm{WS}_{2}$ nanosheets embedded in a mesoporous CMK-3 matrix. Chemistry 2017, 23 (29), 7074-7080.

40. Xu, X. D.; Li, X. J.; Zhang, J. Q.; Qiao, K.; Han, D. Z.; Wei, S. T.; Xing, W.; Yan, Z. F., Surfactant assisted electrospinning of $\mathrm{WS}_{2}$ nanofibers and its promising performance as anode material of sodium-ion batteries. Electrochim. Acta 2019, 302, 259-269.

41. Liang, J.; Wei, Z.; Wang, C.; Ma, J., Vacancy-induced sodium-ion storage in N-doped carbon nanofiber@ $\mathrm{MoS}_{2}$ nanosheet arrays. Electrochim. Acta 2018, 285, 301-308.

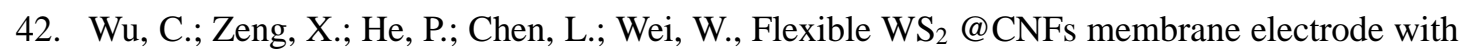
outstanding lithium storage performance derived from capacitive behavior. Adv. Mater. Interfaces 2018, 5 (3) 1701080.

43. Zhou, S.; Chen, J.; Gan, L.; Zhang, Q.; Zheng, Z.; Li, H.; Zhai, T., Scalable production of self-supported $\mathrm{WS}_{2} / \mathrm{CNFs}$ by electrospinning as the anode for high-performance lithium-ion batteries. Science Bulletin 2016, 61 (3), 227-235.

44. Yu, X.; Pei, C.; Chen, W.; Feng, L., 2 dimensional $\mathrm{WS}_{2}$ tailored nitrogen-doped carbon nanofiber as a highly pseudocapacitive anode material for lithium-ion battery. Electrochim. Acta 2018, 272, 119-126.

45. Ma, J.; Zhang, J.; Wang, S.; Wang, T.; Lian, J.; Duan, X.; Zheng, W., Topochemical preparation of $\mathrm{WO}_{3}$ nanoplates through precursor $\mathrm{H}_{2} \mathrm{WO}_{4}$ and their gas-sensing performances. $J$. Phys. Chem. C 2011, 115 (37), 18157-18163.

46. Wei, Z.; Zhang, Y.; Wang, S.; Wang, C.; Ma, J., Fe-doped phosphorene for the nitrogen reduction reaction. J. Mater. Chem. A 2018, 6 (28), 13790-13796.

47. Kresse, G.; Hafner, J., Ab initio molecular dynamics for liquid metals. Phys. Rev. B 1993, 47 (1), 558-561.

48. Perdew, J. P.; Burke, K.; Ernzerhof, M., Generalized gradient approximation made simple Phys. Rev. Lett. 1996, 77, 3865.

49. Blöchl, P. E., Projector augmented-wave method. Phys. Rev. B 1994, 50 (24), 17953-17979.

50. Kresse, G.; Joubert, D., From ultrasoft pseudopotentials to the projector augmented-wave 
method. Phys. Rev. B 1999, 59 (3), 1758.

51. Malard, L. M.; Pimenta, M. A.; Dresselhaus, G.; Dresselhaus, M. S., Raman spectroscopy in graphene. Phys. Rep. 2009, 473 (5-6), 51-87.

52. Yu, X.-G.; Xie, J.-Y.; Yang, J.; Huang, H.-J.; Wang, K.; Wen, Z.-S., Lithium storage in conductive sulfur-containing polymers. J. Electroanal. Chem. 2004, 573 (1), 121-128.

53. Piaggio, P; Cuniberti, C.; Dellepiane, G.; Campani, E.; Gorini, G.; Masetti, G.; M. Novi, M.; Petrillo, G., Vibrational spectra and assignment of poly-(p-phenylene sulfide) and its oligomers. Spectrochim. Acta 1989, 45A (3), 347-356.

54. Ma, R.; Fan, L.; Wang, J.; Lu, B., Confined and covalent sulfur for stable room temperature potassium-sulfur battery. Electrochim. Acta 2019, 293, 191-198.

55. Tan, H.; Tang, J.; Zhou, X.; Golberg, D.; Bhatia, S. K.; Sugahara, Y.; Yamauchi, Y., Preparation of 3D open ordered mesoporous carbon single-crystals and their structural evolution during ammonia activation. Chem. Commun. 2018, 54 (68), 9494-9497.

56. Fu, L.; Tang, K.; Song, K.; van Aken, P. A.; Yu, Y.; Maier, J., Nitrogen doped porous carbon fibres as anode materials for sodium ion batteries with excellent rate performance. Nanoscale 2014, 6 (3), 1384-1389.

57. Xia, X.; Chao, D.; Zhang, Y.; Zhan, J.; Zhong, Y.; Wang, X.; Wang, Y.; Shen, Z. X.; Tu, J.; Fan, H. J., Generic synthesis of carbon nanotube branches on metal oxide arrays exhibiting stable high-rate and long-cycle sodium-ion storage. Small 2016, 12 (22), 3048-58.

58. Augustyn, V.; Simon, P.; Dunn, B., Pseudocapacitive oxide materials for high-rate electrochemical energy storage. Energ Environ. Sci. 2014, 7 (5).

59. Lei, W.; Xiao, W.; Li, J.; Li, G.; Wu, Z.; Xuan, C.; Luo, D.; Deng, Y. P.; Wang, D.; Chen, Z., Highly nitrogen-doped three-dimensional carbon fibers network with superior sodium storage capacity. ACS Appl Mater Interfaces 2017, 9 (34), 28604-28611.

60. Yao, Y.; Xu, R.; Chen, M.; Cheng, X.; Zeng, S.; Li, D.; Zhou, X.; Wu, X.; Yu, Y., Encapsulation of $\mathrm{SeS}_{2}$ into nitrogen-doped free-standing carbon nanofiber film enabling long cycle life and high energy density K-SeS 2 battery. ACS Nano 2019, 13 (4), 4695-4704.

61. Cui, J.; Yao, S.; Ihsan-Ul-Haq, M.; Wu, J.; Kim, J.-K., Correlation between Li plating behavior and surface characteristics of carbon matrix toward stable Li metal anodes. Adv. Energy Mater. 2019, 9 (1) 1802777.

62. Jin, T.; Li, H. X.; Li, Y.; Jiao, L. F.; Chen, J., Intercalation pseudocapacitance in flexible and self-standing $\mathrm{V}_{2} \mathrm{O}_{3}$ porous nanofibers for high-rate and ultra-stable $\mathrm{K}$ ion storage. Nano Energy 2018, 50, 462-467.

63. Wu, Y.; Hu, S.; Xu, R.; Wang, J.; Peng, Z.; Zhang, Q.; Yu, Y., Boosting potassium-ion battery performance by encapsulating red phosphorus in free-standing nitrogen-doped porous hollow carbon nanofibers. Nano Lett. 2019, 19 (2), 1351-1358. 


\section{Supporting information}

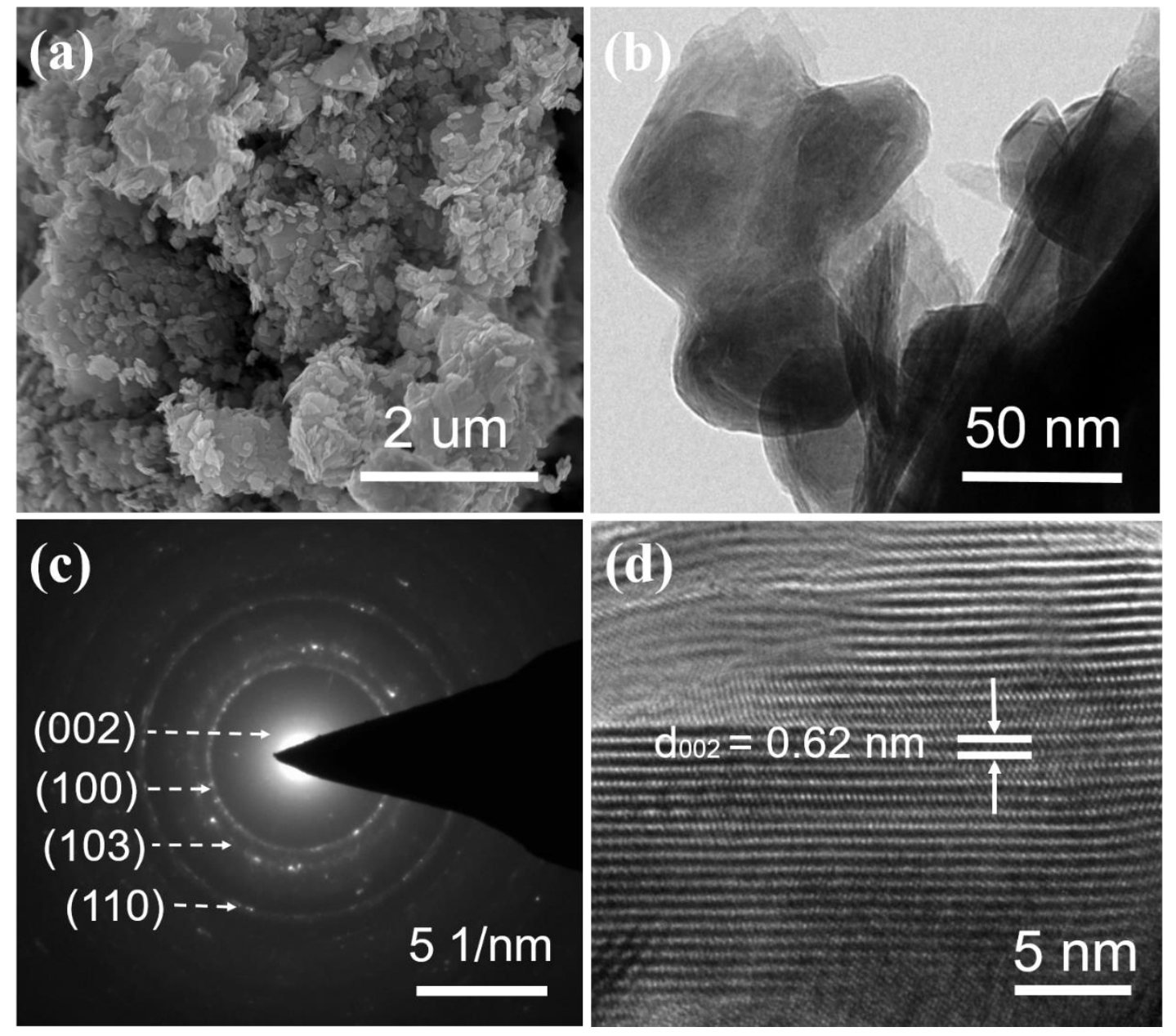

Figure S1 (a) low-resolution SEM image and (b) TEM image of pure $\mathrm{WS}_{2}$; (c) electron diffraction pattern, and (d) high-resolution TEM image of pure $\mathrm{WS}_{2}$. 


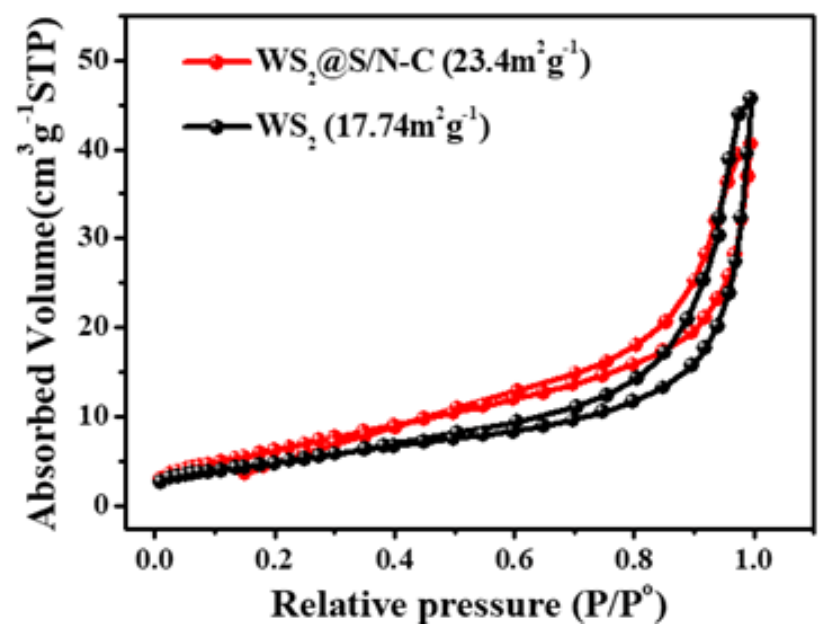

Figure S2 Nitrogen adsorption and desorption isotherms of $\mathrm{WS}_{2} @ \mathrm{~S} / \mathrm{N}-\mathrm{C}$ nanofibers and pure $\mathrm{WS}_{2}$. 

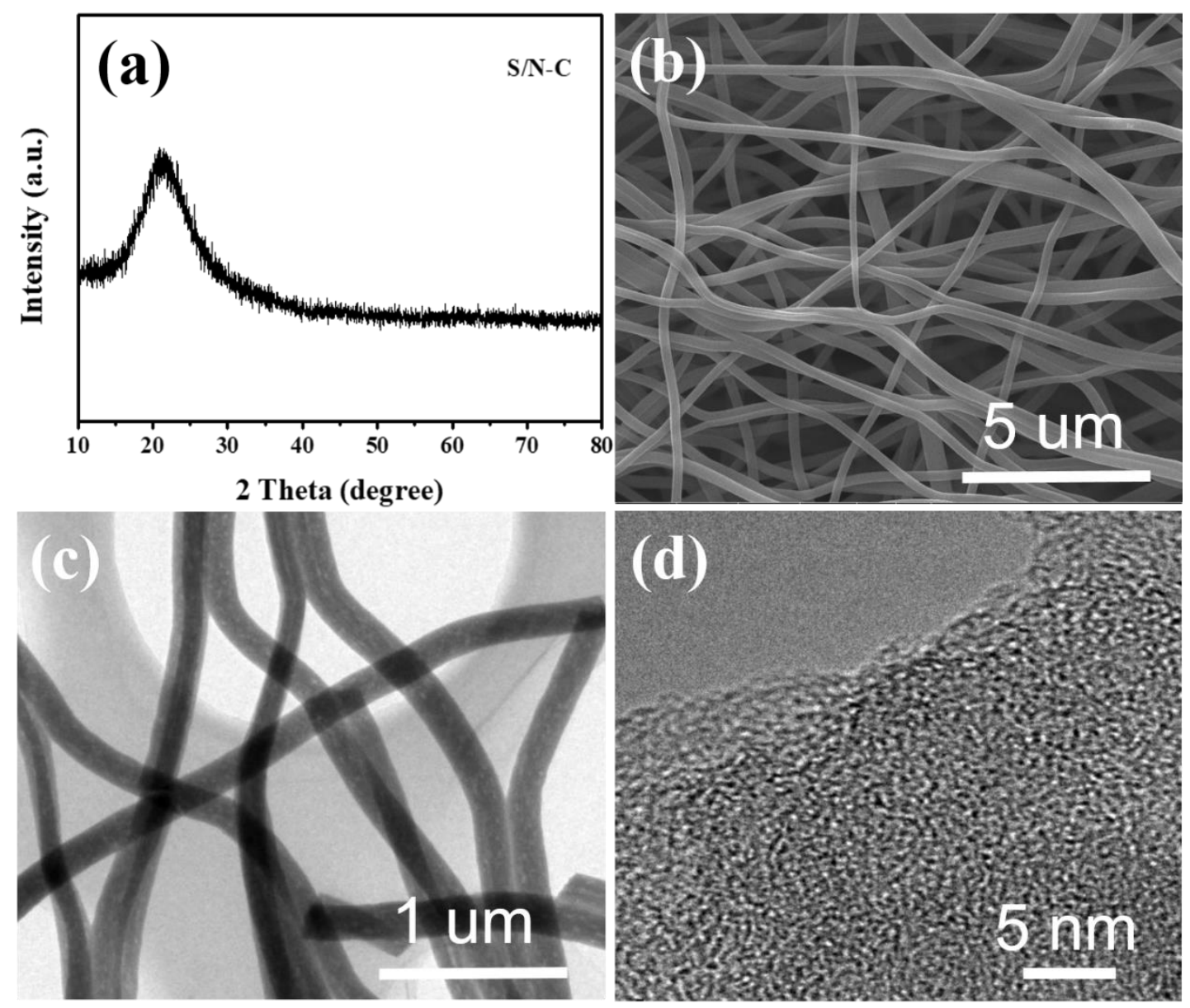

Figure S3 Characterizations of S/N-C nanofibers: (a) XRD pattern; (b) SEM image; (c) TEM image and (d) HR-TEM image. 


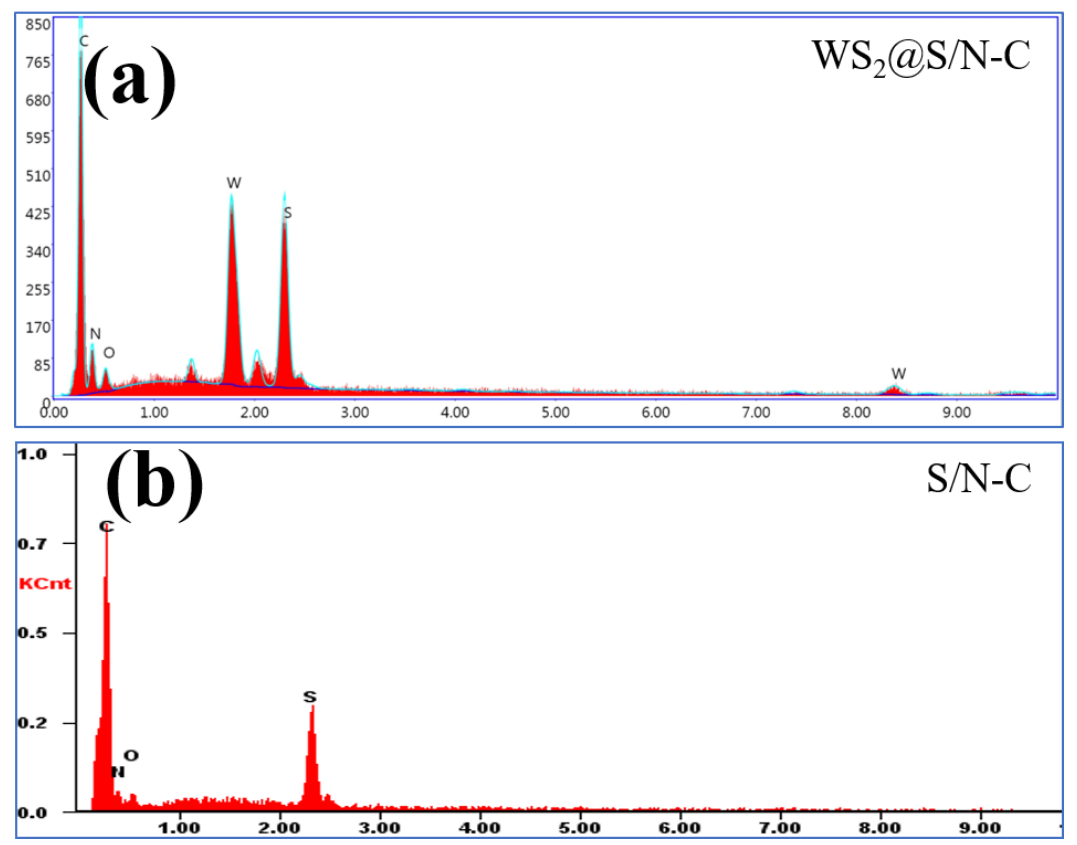

Figure S4 EDS spectrum of (a) WS $\mathrm{W}_{2} @ \mathrm{~S} / \mathrm{N}-\mathrm{C}$ nanofibers and (b) S/N-C nanofibers. 

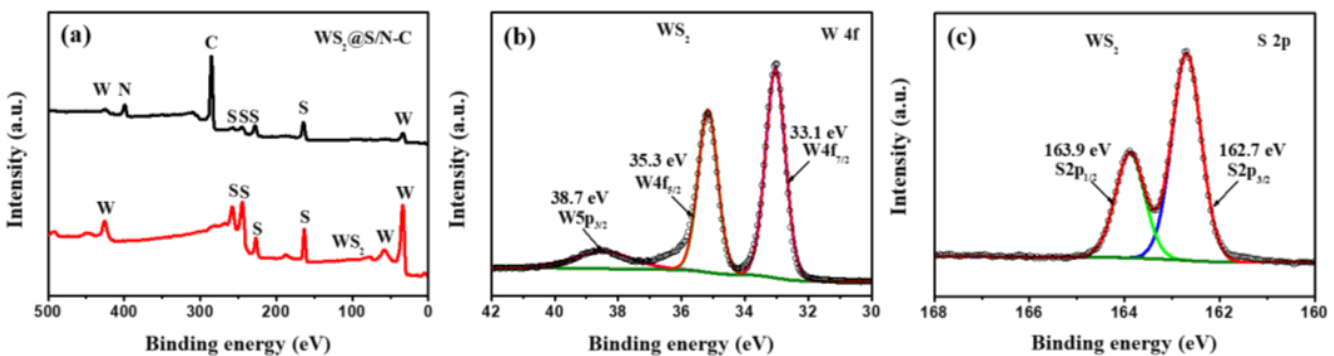

Figure S5 (a) XPS full survey spectra of $\mathrm{WS}_{2} @ \mathrm{~S} / \mathrm{N}-\mathrm{C}$ nanofibers and pure $\mathrm{WS}_{2}$; (b and c) High-resolution XPS spectra of W and S elements for pure $\mathrm{WS}_{2}$. 


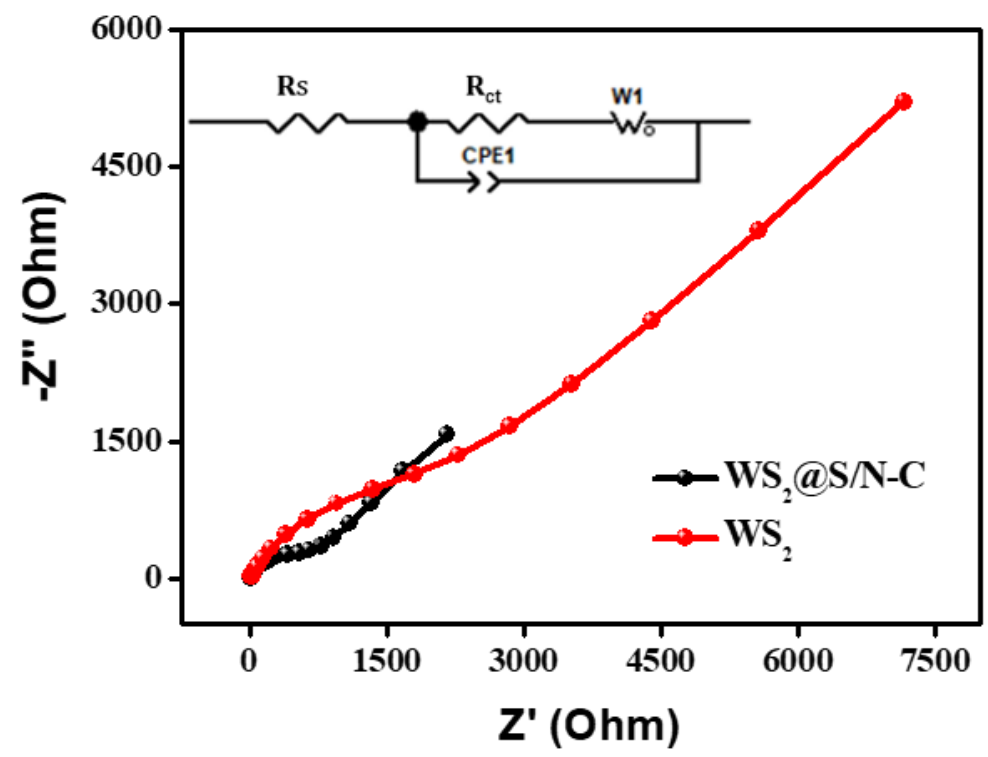

Figure S6 EIS spectra for $\mathrm{WS}_{2} @ \mathrm{~S} / \mathrm{N}-\mathrm{C}$ and pure $\mathrm{WS}_{2}$ after cycling for 1 cycle at $0.1 \mathrm{~A} \mathrm{~g}^{-1}$. The inset is the equivalent circuit. 

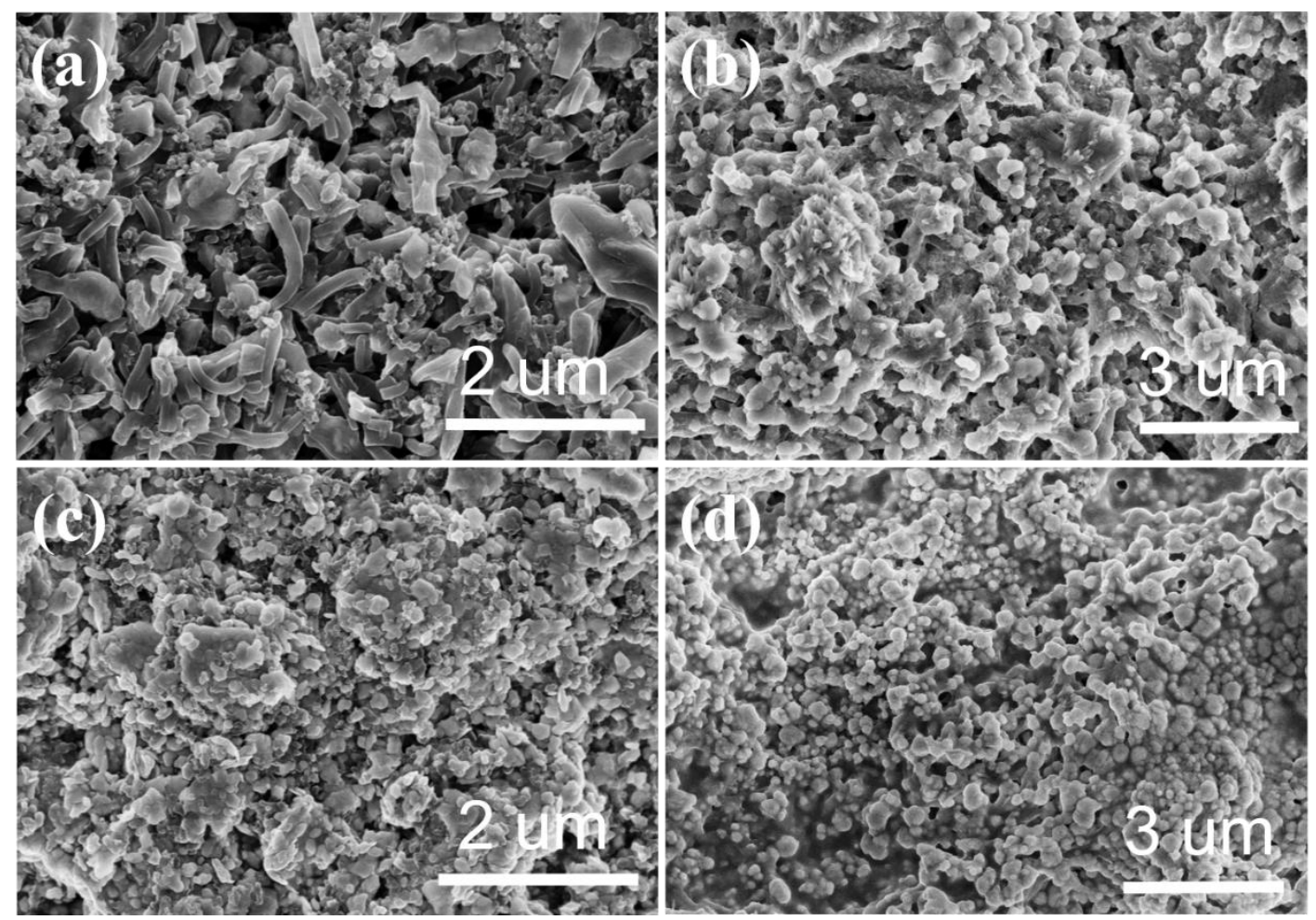

Figure S7 Low-resolution SEM images of WS $\mathrm{W}_{2} @ \mathrm{~S} / \mathrm{N}-\mathrm{C}$ electrode: (a) fresh electrode and (b) cycled electrode after 100 cycles; low-resolution SEM images of $\mathrm{WS}_{2}$ electrode: (c) fresh electrode and (d) cycled electrode after 100 cycles. 
Table S1. The adsorption behavior of $\mathrm{Na}$ on pristine $\mathrm{WS}_{2}$.

\begin{tabular}{|c|c|c|c|}
\hline $\mathrm{WS}_{2}$ & Idsorption sites & II (S-top) & III (W-top) \\
\hline $\mathrm{E}_{\mathrm{ad}}(\mathrm{eV})$ & -0.494 & -0.744 & -0.759 \\
\hline $\mathrm{Q}_{\mathrm{Na}}(|\mathrm{e}|)$ & 0.56 & 0.74 & 0.76 \\
\hline
\end{tabular}

Table S2. The adsorption behavior of Na on $\mathrm{WS}_{2} @ \mathrm{~S} / \mathrm{N}-\mathrm{C}$

\begin{tabular}{|c|c|c|c|}
\hline Adsorption sites & I (S-top) & II (Hollow) & III (W-top) \\
\hline $\mathrm{WS}_{2} @ \mathrm{~S} / \mathrm{N}-\mathrm{C}$ & -0.897 & -1.168 & -1.208 \\
\hline $\mathrm{E}_{\mathrm{ad}}(\mathrm{eV})$ & 0.65 & 0.79 & 0.79 \\
\hline
\end{tabular}

